\title{
EFFECT OF ORGANIC MATTER, BIO-FERTILIZERS AND MAGNETIC WATER ON THE VEGETATIVE GROWTH AND FLOWER QUALITY OF GLADIOLUS (GLADIOLUS HYBRIDA L.) VAR. CARTAGO
}

\author{
Ahmmad, C. A. - ABdullatif, S. A.* \\ University of Sulaimani, Kurdistan, Iraq \\ *Corresponding author \\ e-mail: chnwr.ahmmad@univsul.edu.iq \\ (Received $5^{\text {th }}$ Aug 2019; accepted $28^{\text {th }}$ Nov 2019)
}

\begin{abstract}
The experiment was conducted to investigate the effects of poultry manure (without Poultry manure $A_{0}, 2 \%$ poultry manure $A_{1}$ and $4 \%$ poultry $A_{2}$ ), bio-fertilizers (not inoculation corms by bacteria $B_{0}$, inoculation corms by bacteria Azospirillum brasilense $\mathrm{B}_{1}$, and inoculation corms by Bacillus subtilis $\mathrm{B}_{2}$ ) and type of irrigation (tap water $\mathrm{C}_{1}$ and magnetic water treated by 500 gauss $\mathrm{C}_{2}$ ) on cut flowers and vase life of Gladiolus flowers Cartago cultivar in two seasons (autumn 2016 and spring 2017) The field experiment was laid down in a factorial $2 * 3 * 3$ in Split plot Randomized Complete Block Design (RCBD) with three replications and seven plants for each treatment. Results showed a significant increase in vegetative growth (Plant height, Leaf dry matter, Leaf chlorophyll intensity, N, P and K concentration in the leaves) and flower quality (number of days to flowering, anthocyanin concentration in petals (mg.100 $\mathrm{g}^{-1}$ ), basal floral diameter and vase life), these due to effect of plants with $2 \%$ poultry manure, inoculation by bacteria and irrigation with magnetic water. Decreasing in vegetative and flowering characteristics was also observed, when Poultry manure was used at $4 \%$ rate and without inoculation by bacteria and irrigation by tap water. But the magnetic water reduced the negative effect.
\end{abstract}

Keywords: Azospirillum, Bacillus, cut flower, soil media, irrigation

\section{Introduction}

Gladiolus (Gladiolus hybrida L.) belonging to family Irridaceae, it is a monocotyledonous, perennial bulbous flowering plant (Manning and Goldblatt, 2008). are one of the most important flowering plants that are used worldwide for cut flowers production, as they rank among of the top ten best cut flowers due to their different shapes, dazzling colors, varying sizes and excellent vase life. There is a considerable demand in both domestic and export production (Ali et al., 2014). For an amount of 16 million dollars, 60 million gladiolus spikes were sold in the United States of America (Sajjad et al., 2014). The success of gladiolus cultivation depends on many factors like soil fertility, irrigation, planting time, planting density, plant protection, plant growth regulators and some chemicals, these may play major role towards increasing production and quality of gladiolus. But, biofertilzers have positive impact on availability of nutrients (Bhalla et al., 2006). Organic fertilizers including farmyard manure, and poultry manure, sheep manure may be used for the crop production as a substitute of the chemical fertilizer because the importance of the organic manures cannot be overlooked. In recent year organic matter as a suitable source of nutrients to the soil has been replaced by chemical fertilizers that positively affect both the chemical and physical properties of the soil such as soil structure (Bot and Benites, 2005).

The emphasis is now focused on the use biofertilizers like Azotobacter, Azospirillium and phosphate solubilizing bacteria (PSB). Species of Bacillus is known to promote plant growth. The principal mechanisms of growth promotion include production of growth 
stimulating phytohormones, solubilization and mobilization of phosphate, siderophore production, production of antibiotics, inhibition of plant ethylene synthesis, and induction of plant systemic resistance to pathogens (Gutiérrez-Mañero et al., 2001). Azospirillum is a symbiotic $\mathrm{N}$-fixing bacterium. Azotobacter and Azospirillum fix atmospheric nitrogen when inoculated to plants, which help to save the application of $\mathrm{N}$-fertilizers to an extent of 20-25 percent (Chaitra and Patil, 2007).

The magnetic water technology is wide studied subject throughout the world, especially in major countries like China, USA, and Australia (Hozayn and Qados, 2010). A magnetic field is an unpreventable environmental factor for plants in the soil. However, its impact on plant growth (Eşitken and Turan, 2004). Magnetic treatment results in changes in structure of the water, such as changes the formation of clustering structures from linear and ring hydrogen-bound chains of molecules, the magnetic interaction between these clustering structures and increasing polarization effects of water molecules (Pang and Deng, 2008). Magnetic fields have a positive effect on plant characteristics such as seed germination, seedling growth, agronomic traits and seed yield (Aladjadjiyan, 2002; Tahir and Karim, 2010).

The postharvest longevity of flowers has a critical importance in determining the value of the crop. Cut flowers are highly perishable commodities and are highly vulnerable to postharvest losses. It is estimated that nearly $70 \%$ of the potential lasting quality of cut flowers is pre-determined at harvest while postharvest factors influence $30 \%$ of the quality. In cut flower trade, it is very important to maintain freshness and original colors of flowers for the longer period, throughout the postharvest chain. Harvesting of flowers at an optimum stage of bud development (Kumari, 2014).

The aim of this study is to determine the effect of various amounts of poultry manure, bio-fertilizer and magnetic water processor on the growth characteristics and flower quality of gladiolus plants of the Cartago cultivar.

\section{Materials and methods}

\section{The experiment sites}

The experiment was conducted at the College of Agricultural Engineering Sciences, Sulaimani University, Kurdistan, Iraq in greenhouse for two seasons first period in $7^{\text {th }}$ of October 2016 to May 2017 (autumn), second study in 5th of March 2017 to August 2017 (spring). The area is located at $35^{\circ} 3214^{\prime \prime} \mathrm{N}, 45^{\circ} 2197^{\prime} \mathrm{E}$, and an altitude of (743.40 M) above sea level, with GPS reading.

The experiment was conducted to investigate the effects of poultry manure, $\left(\mathrm{A}_{0}\right.$ without poultry manure, $\mathrm{A}_{1}$ poultry manure at $2 \%$ of soil weight, $\mathrm{A}_{2}$ poultry manure at $4 \%$ of soil weight), biofertilizers ( $\mathrm{B}_{0}$ without inoculation, $\mathrm{B}_{1}$ inoculation by Azospirillum brasilense, $\mathrm{B}_{2}$ inoculation by Bacillus subtilis) and water processor magnetic $\left(\mathrm{C}_{1}\right.$ irrigation by tap water, $\mathrm{C}_{2}$ irrigation by magnetic water) and its impact on the vegetative and flower quality of Gladiolus hybrida. These treatments were randomized in a split plot design with three replicates, were irrigation types contributed as the main plots, while interaction of poultry manure and biofertilizers $(\mathrm{A} * \mathrm{~B})$ were distributed in the sub plots.

The magnetic water treatment was conducted by passing the irrigation water through magnetic flux densities 500 Gauss. A local magnetic device is special magnets spaced a part and parallel to the length of water carrying copper pipe. 


\section{Planting the corms}

Planting the corms in the plastic bags (4 $\mathrm{kg}$ size) were filled from the soil agriculture consisting of the three levels, first was consisting of soil and Peatmoos in equal proportions. The second media was composed of the soil and Peatmoos in equal proportions plus poultry manure at $2 \%$ and the third level was consisting of soil and Peatmoss in equal proportions with $4 \%$ of poultry manure based on soil weight. Analysis of the physical and chemical properties of three soil media is shown in Table 1.

Table1. The main physical and chemical properties of three soil media

\begin{tabular}{|c|c|c|c|c|}
\hline Soil properties & Units & $\begin{array}{l}\text { Without poultry } \\
\text { manure }\end{array}$ & $\begin{array}{l}2 \% \text { poultry } \\
\text { manure }\end{array}$ & $\begin{array}{l}4 \% \text { poultry } \\
\text { manure }\end{array}$ \\
\hline Sand & \multirow{3}{*}{$\%$} & 34.40 & 30.40 & 32.40 \\
\hline Silt & & 34.00 & 32.00 & 46.00 \\
\hline Clay & & 31.60 & 37.60 & 21.60 \\
\hline Texture & & Loam clay & Loamy clay & Loamy \\
\hline $\mathrm{EC}$ & $\mathrm{dsm}^{-1}$ & 2.52 & 1.70 & 2.91 \\
\hline $\mathrm{pH}$ & & 7.33 & 7.13 & 7.18 \\
\hline \multicolumn{5}{|l|}{ Cation } \\
\hline $\mathrm{Ca}^{++}$ & & 11.52 & 9.30 & 14.00 \\
\hline $\mathrm{Mg}^{++}$ & & 7.81 & 5.22 & 10.31 \\
\hline $\mathrm{Na}^{+}$ & & 6.22 & 2.31 & 4.34 \\
\hline $\mathrm{K}^{+}$ & \multirow{5}{*}{$\mathrm{mq} / \mathrm{L}$} & 1.14 & 1.03 & 1.11 \\
\hline $\mathrm{Cl}^{-}$ & & 17.50 & 12.50 & 20.32 \\
\hline $\mathrm{HCO}^{-}$ & & 2.30 & 1.50 & 2.54 \\
\hline $\mathrm{CO} 3=$ & & Nil & Nil & Nil \\
\hline $\mathrm{SO} 4=$ & & 4.98 & 3.28 & 5.34 \\
\hline $\mathrm{CaCO} 3$ & $\%$ & 15.22 & 30.19 & 23.41 \\
\hline Organic matter & $\%$ & 0.79 & 0.73 & 0.89 \\
\hline Available nitrogen & & 23.00 & 12.00 & 31.00 \\
\hline Available phosphorus & \multirow{2}{*}{ Mg. $\mathrm{kg}^{-1}$} & 15.25 & 14.70 & 10.13 \\
\hline Soluble potassium & & 87.11 & 79.39 & 68.93 \\
\hline
\end{tabular}

Data were analyzed in the Central Laboratories of College of Agriculture, University of Baghdad

\section{Source of the corms}

The corms of gladiolus var. Cartago were brought from the company of stoop flower bulbs in Holland. Healthy and uniform size 10-12 cm corms are divided in to three groups the first group dipped in the distillates water, second group were dipped in the solution which contain Azospirillum brasilence and the third group were dipped in the solution which contain Bacillus subtilis for half an hour and dried in shade for 30 min before planting.

Planting one corm in the plastic bags in $8 \mathrm{~cm}$ depth (Greving, 1987). Agricultural practices were carried out for all replications, such as weeding and hoeing the surface of the soil, in order to ventilate. Ventilation of the greenhouse was done by opening the doors and slots. Also, air cooler and heater were used to adjust the temperature in the greenhouse in both high and low temperature conditions. Atmospheric condition inside 


$$
\text { - } 2640 \text { - }
$$

the greenhouse had been measured by recording maximum and minimum temperatures and relative humidity.

\section{Experimental parameters}

The experimental parameters are presented in Table 2.

Table 2. Study parameters

\begin{tabular}{|c|c|}
\hline Parameters & Methods \\
\hline Plant height $(\mathrm{cm})$ & $\begin{array}{l}\text { Measured from the soil surface to the end of the flower spike } \\
\text { length }\end{array}$ \\
\hline Leaf dry mater $(\%)$ & Dry matter $(\%)=\frac{\text { dry weight of leaves }}{\text { fresh weight of leaves }} \times 100$ \\
\hline Chlorophyll (spad unit) & Portable chlorodhyll meter CCM-200 plus. OPTI-SCIENCES \\
\hline Nitrogen concentration in leaves $(\%)$ & Micro-Kjeldahl (Page et al., 1982) \\
\hline Phosphorus concentration in leaves $(\%)$ & Spectrophotometer at $(882 \mathrm{\eta m})$ wavelength (Olsen et al., 1982) \\
\hline Potassium concentration in leaves $(\%)$ & Flame Photometer (Page et al., 1982) \\
\hline Number of days for flowering (day) & $\begin{array}{l}\text { We have counted the days from the first day of planting unit } \\
\text { the first appearance of the basal floret's color }\end{array}$ \\
\hline $\begin{array}{l}\text { Anthocyanin concentration in flower } \\
\text { petals }\left(\mathrm{mg} .100 \mathrm{~g}^{-1}\right)\end{array}$ & Spectrophotometer (Ranganna, 1977) method \\
\hline Basal floral diameter $(\mathrm{cm})$ & Digital caliper vernier \\
\hline Vase life (day) & $\begin{array}{l}\text { Measured by the number of days after harvesting the flower as } \\
\text { until } 3 / 4 \text { of the florets are wilted }\end{array}$ \\
\hline
\end{tabular}

\section{Preparation of bacterial inoculants}

Pure isolated bacteria were taken from the laboratories of the Agricultural Research Center- Baghdad- Zaafaraniyah associated to the ministry of Science and Technology, Iraq.

\section{Inoculants corms by bacteria Azospirillum brasilense and Bacillus subtilis}

- Preparation of $1 \mathrm{~L}$ of nutrient solution, $25 \mathrm{~g}$ of nutrient broth was dissolved in one litter of distilled water and sterilized by using autoclave with the pressure of 1.5 bar at temperature $121{ }^{\circ} \mathrm{C}$ for 15 min before adding bacteria.

- Adding $6 \mathrm{~cm}^{3}$ of bacteria to the cultural media (liquid nutrient broth) and shaken for $15 \mathrm{~min}$.

- Then the bacterial culture putted in an incubator at $28^{\circ} \mathrm{C}$ for $72 \mathrm{~h}$.

- After inoculation period $3 \mathrm{~g}$ of sugar and $2 \mathrm{~g}$ of Arabic gum were added to the bacteria suspension shake it for 30-60 min. The bacteria inoculants ready to use.

\section{Description of the experiment}

The field experiment was carried out based on the Split plot randomized complete block design (RCBD) with three replications and seven plants for each treatment. The data were analyzed by a computer program Statistical Analysis System (SAS) and the comparisons among means were carried out by the least significant difference (L.S.D) at $\mathrm{P} \leq 0.05$ (Table 2). 


$$
-2641 \text { - }
$$

\section{Results}

\section{Effect of poultry manure, bio-fertilizers and magnetic water and their interaction on the plant height $(\mathrm{cm})$}

Table 3 illustrates that using $\mathrm{A}_{1}$ treatment which is $2 \%$ of poultry manure has a significant effect on plant height 124.74 and $139.58 \mathrm{~cm}$ for autumn and spring respectively compared to control $\mathrm{A}_{0} 120.26$ and $134.68 \mathrm{~cm}$. In addition, it was noticed that plant height after using $\mathrm{A}_{1}$ was significantly different as compared to using $4 \%$ of poultry manure $\mathrm{A}_{2} 98.38,133.91 \mathrm{~cm}$ for both seasons respectively.

Regarding the inoculation of gladiolus corms with bacteria Azospirillum brasilense and Bacillus subtilis, the maximum plant height values are 116.89, 117.11 and 138.85, $137.15 \mathrm{~cm}$ in autumn and spring respectively. These results are significantly different from control $\mathrm{B}_{0}$ (without inoculation by bacteria), which are 109.38 and $132.16 \mathrm{~cm}$ in both seasons. With regard to irrigation, using magnetic water $\mathrm{C}_{2}$ significantly increases plant height $118.07,138.08 \mathrm{~cm}$ as compared to $C_{1}$ which gave $110.85,134.02 \mathrm{~cm}$ in autumn and spring season respectively. The significant effect of interaction of organic matter, bio-fertilizers, and magnetic water on plant height of gladiolus shown in the same table, the highest plants $132.88,145.90 \mathrm{~cm}$ were achieved from $\mathrm{A}_{1} \mathrm{~B}_{1} \mathrm{C}_{2}$ for both seasons, respectively. While the lowest plant height $93.49 \mathrm{~cm}$ was noticed from $\mathrm{A}_{2} \mathrm{~B}_{0} \mathrm{C}_{1}$ in the autumn and $128.94 \mathrm{~cm}$ from $\mathrm{A}_{0} \mathrm{~B}_{0} \mathrm{C}_{1}$ in the spring.

Table 3. Effect of poultry manure, bio-fertilizers and magnetic water and their interaction on the plant height $(\mathrm{cm})$ in two seasons

\begin{tabular}{|c|c|c|c|c|c|c|c|c|c|c|c|c|c|c|}
\hline \multicolumn{10}{|c|}{ Autumn } & \multicolumn{5}{|c|}{ Spring } \\
\hline $\mathrm{C}$ & A & \multicolumn{2}{|c|}{$\mathrm{B}_{0}$} & \multicolumn{2}{|c|}{$\mathrm{B}_{1}$} & \multicolumn{2}{|c|}{$\mathrm{B}_{2}$} & $\mathrm{~A}^{*} \mathrm{C}$ & $\mathrm{C}$ & $\mathrm{B}_{0}$ & $\mathrm{~B}_{1}$ & $\mathrm{~B}_{2}$ & $A^{*} \mathrm{C}$ & $\mathrm{C}$ \\
\hline \multirow{3}{*}{$\mathrm{C}_{1}$} & $\mathrm{~A}_{0}$ & \multicolumn{2}{|c|}{110.07} & \multicolumn{2}{|c|}{117.00} & \multicolumn{2}{|c|}{118.10} & 115.05 & \multirow{3}{*}{$\begin{array}{l}\vec{\sigma} \\
\underset{\infty}{u}\end{array}$} & 128.94 & 132.32 & 131.44 & 130.90 & \multirow{3}{*}{$\frac{\vec{\omega}}{\stackrel{+}{\circ}}$} \\
\hline & $\mathrm{A}_{1}$ & \multicolumn{2}{|c|}{112.00} & \multicolumn{2}{|c|}{122.67} & \multicolumn{2}{|c|}{126.00} & 120.22 & & \begin{tabular}{|l|}
131.73 \\
\end{tabular} & 142.67 & 139.09 & 137.83 & \\
\hline & $\mathrm{A}_{2}$ & \multicolumn{2}{|c|}{93.49} & \multicolumn{2}{|c|}{99.95} & \multicolumn{2}{|c|}{98.40} & 97.28 & & 131.68 & 133.33 & 135.00 & 133.33 & \\
\hline \multirow{3}{*}{$\mathrm{C}_{2}$} & $\mathrm{~A}_{0}$ & \multicolumn{2}{|c|}{118.51} & \multicolumn{2}{|c|}{128.86} & \multicolumn{2}{|c|}{129.03} & 125.47 & - & 133.53 & 141.89 & 139.94 & 138.45 & - \\
\hline & $\mathrm{A}_{1}$ & 12 & & 132 & & 130 & & 129.25 & $\ddot{0}$ & 137.11 & 145.90 & 140.96 & 141.33 & $\underset{0}{\infty}$ \\
\hline & $\mathrm{A}_{2}$ & 97 & & 99. & & 100 & & 99.48 & & 130.00 & 137.00 & 136.44 & 134.48 & \\
\hline & & & & eract & on $\mathrm{O}$ & $\mathrm{C}^{*} \mathrm{~B}$ & & & & & Inter & action of & $\mathrm{C} * \mathrm{~B}$ & \\
\hline $\mathrm{C}_{1}$ & 10 & & & 3.21 & & 1.17 & & & & 30.78 & 136.11 & 135.18 & & \\
\hline $\mathrm{C}_{2}$ & 113 & & & 0.56 & & .06 & & & & 33.55 & 141.60 & 139.12 & & \\
\hline & & eract & on & $A * B$ & & & & $A$ & & Interac & tion of $\mathrm{A}$ & & & A \\
\hline $\mathrm{A}_{0}$ & 11 & & & .93 & & .57 & & 0.26 & 131.2 & & 37.11 & 135.69 & & 134.68 \\
\hline $\mathrm{A}_{1}$ & 118 & & & .78 & 12 & .14 & & 4.74 & 134.4 & & 44.29 & 140.03 & & 139.58 \\
\hline $\mathrm{A}_{2}$ & & & & 95 & & 63 & & .38 & 130.8 & & 35.17 & 135.72 & & 133.91 \\
\hline $\mathrm{B}$ & 105 & & & .89 & $11^{\prime}$ & .11 & & & 132.1 & & 38.85 & 137.15 & & \\
\hline
\end{tabular}

\begin{tabular}{c|c|c|c|c|c|c|c|c|c|c|c|c|c}
\hline $\mathrm{A}$ & $\mathrm{B}$ & $\mathrm{C}$ & $\mathrm{A} * \mathrm{~B}$ & $\mathrm{~A} * \mathrm{C}$ & $\mathrm{B} * \mathrm{C}$ & $\mathrm{A} * \mathrm{~B} * \mathrm{C}$ & $\mathrm{A}$ & $\mathrm{B}$ & $\mathrm{C}$ & $\mathrm{A} * \mathrm{~B}$ & $\mathrm{~A} * \mathrm{C}$ & $\mathrm{B} * \mathrm{C}$ & $\mathrm{A} * \mathrm{~B} * \mathrm{C}$ \\
\hline 3.53 & 3.53 & 2.88 & 7.99 & 6.15 & 12.57 & 9.22 & 3.91 & 3.91 & 3.19 & 6.81 & 5.67 & 5.65 & 9.45 \\
\hline
\end{tabular}

A is poultry manure, A0 without poultry manure, A1 application of poultry manure at $2 \%$ of soil weight, A 2 application of poultry manure at $4 \%$ of soil weight. B is bio-fertilizers, B1 is inoculation by bacteria Azospirillum brasilense, B2 is inoculation by bacteria Bacillus subtilis, C is type of irrigation, C1 is irrigation by tap water, $\mathrm{C} 2$ is irrigation by magnetic water 


\section{Effect of poultry manure, bio-fertilizers and magnetic water and their interaction on leaf dry matter \%}

Table 4 shows that planting the corms in medium containing $2 \%$ of poultry manure $\mathrm{A}_{1}$ has a significant effect on leaf dry matter. The highest value $24.54,26.95 \%$ were found from $A_{1}$ for autumn and spring respectively, while the lowest value $20.84 \%$ was achieved from $\mathrm{A}_{2}$ in the autumn and $22.71 \%$ was found from $\mathrm{A}_{0}$ in spring. Inoculation of gladiolus corms with Azospirillum brasilense $\mathrm{B}_{1}$ significantly affected the percentage of the leaf dry matter which were $22.94,25.71 \%$ for both seasons. Also, the inoculation by Bacillus subtilis $\mathrm{B}_{2}$, significantly affected the percentage of the leaf dry matter $23.57,25.69 \%$ as compared to control $\mathrm{B}_{0} 20.50,21.89 \%$ for both seasons respectively.

Table 4. Effect of poultry manure, bio-fertilizers and magnetic water and their interaction on leaf dry matter \% of Gladiolus in two seasons

\begin{tabular}{|c|c|c|c|c|c|c|c|c|c|c|c|}
\hline \multicolumn{7}{|c|}{ Autumn } & \multicolumn{5}{|c|}{ Spring } \\
\hline $\mathrm{C}$ & $\mathrm{A}$ & $\mathrm{B}_{0}$ & $\mathrm{~B}_{1}$ & $\mathrm{~B}_{2}$ & $\mathrm{~A} * \mathrm{C}$ & $\mathrm{C}$ & $\mathrm{B}_{0}$ & $\mathrm{~B}_{1}$ & $\mathrm{~B}_{2}$ & $\mathrm{~A} * \mathrm{C}$ & $\mathrm{C}$ \\
\hline \multirow{3}{*}{$\mathrm{C}_{1}$} & $\mathrm{~A}_{0}$ & 18.43 & 20.52 & 21.78 & 20.24 & \multirow{3}{*}{$\begin{array}{l}\text { ? } \\
\text { ర్ }\end{array}$} & 19.14 & 21.69 & 21.87 & 20.90 & \multirow{3}{*}{$\stackrel{N}{N}$} \\
\hline & $\mathrm{A}_{1}$ & 22.12 & 23.87 & 24.17 & 23.39 & & 21.77 & 25.51 & 27.56 & 24.94 & \\
\hline & $\mathrm{A}_{2}$ & 17.79 & 19.89 & 20.12 & 19.26 & & 17.90 & 22.63 & 22.09 & 20.87 & \\
\hline \multirow{3}{*}{$\mathrm{C}_{2}$} & $\mathrm{~A}_{0}$ & 20.42 & 23.74 & 24.93 & 23.03 & \multirow{3}{*}{$\underset{\omega}{\varpi}$} & 23.05 & 25.20 & 25.31 & 24.52 & \multirow{3}{*}{ న్ } \\
\hline & $\mathrm{A}_{1}$ & 23.71 & 26.13 & 27.20 & 25.68 & & 26.09 & 30.46 & 30.32 & 28.96 & \\
\hline & $\mathrm{A}_{2}$ & 20.51 & 23.52 & 23.20 & 22.41 & & 23.39 & 28.78 & 26.99 & 26.39 & \\
\hline \multicolumn{7}{|c|}{ Interaction of $\mathrm{B}^{*} \mathrm{C}$} & \multicolumn{5}{|c|}{ Interaction of $\mathrm{B} * \mathrm{C}$} \\
\hline \multicolumn{2}{|c|}{$\mathrm{C}_{1}$} & 19.45 & 21.43 & 22.02 & & & 19.60 & 23.28 & 23.84 & & \\
\hline \multicolumn{2}{|c|}{$\overline{C_{2}}$} & 21.55 & 24.46 & 25.11 & & & 24.18 & 28.15 & 27.54 & & \\
\hline \multicolumn{5}{|c|}{ Interaction of $\mathrm{A}^{*} \mathrm{~B}$} & \multicolumn{2}{|c|}{$\mathrm{A}$} & \multicolumn{3}{|c|}{ Interaction of $\mathrm{A} * \mathrm{~B}$} & \multicolumn{2}{|c|}{$\mathrm{A}$} \\
\hline \multicolumn{2}{|c|}{$\mathrm{A}_{0}$} & 19.43 & 22.13 & 23.36 & \multicolumn{2}{|c|}{21.64} & 21.10 & 23.45 & 23.59 & \multicolumn{2}{|c|}{22.71} \\
\hline \multicolumn{2}{|c|}{$\mathrm{A}_{1}$} & 22.92 & 25.00 & 25.69 & \multicolumn{2}{|c|}{24.54} & 23.93 & 27.99 & 28.94 & \multicolumn{2}{|c|}{26.95} \\
\hline \multicolumn{2}{|c|}{$\mathrm{A}_{2}$} & 19.15 & 21.71 & 21.66 & \multicolumn{2}{|c|}{20.84} & 20.64 & 25.71 & 24.54 & \multicolumn{2}{|c|}{23.63} \\
\hline \multicolumn{2}{|c|}{$\mathrm{B}$} & 20.50 & 22.94 & 23.57 & & & 21.89 & 25.71 & 25.69 & & \\
\hline
\end{tabular}

LSD 0.05

\begin{tabular}{c|c|c|c|c|c|c|c|c|c|c|c|c|c}
\hline $\mathrm{A}$ & $\mathrm{B}$ & $\mathrm{C}$ & $\mathrm{A} * \mathrm{~B}$ & $\mathrm{~A} * \mathrm{C}$ & $\mathrm{B} * \mathrm{C}$ & $\mathrm{A} * \mathrm{~B} * \mathrm{C}$ & $\mathrm{A}$ & $\mathrm{B}$ & $\mathrm{C}$ & $\mathrm{A} * \mathrm{~B}$ & $\mathrm{~A} * \mathrm{C}$ & $\mathrm{B} * \mathrm{C}$ & $\mathrm{A} * \mathrm{~B} * \mathrm{C}$ \\
\hline 1.16 & 1.15 & 0.94 & 2.65 & 2.07 & 2.25 & 3.08 & 2.06 & 2.06 & 1.68 & 4.39 & 3.24 & 3.27 & 5.24 \\
\hline
\end{tabular}

A is poultry manure, A0 without poultry manure, A1 application of poultry manure at $2 \%$ of soil weight, A2 application of poultry manure at $4 \%$ of soil weight. B is bio-fertilizers, B1 is inoculation by bacteria Azospirillum brasilense, B2 is inoculation by bacteria Bacillus subtilis, C is type of irrigation, $\mathrm{C} 1$ is irrigation by tap water, $\mathrm{C} 2$ is irrigation by magnetic water

Irrigation by magnetic water $\mathrm{C}_{2}$ has a significant effect on the leaf dry matter 23.71 , $26.62 \%$, while irrigation by tap water $\mathrm{C}_{1}$ gave $20.97,22.24 \%$ for both seasons, respectively. The significant effect of interaction of poultry manure, bio-fertilizers and magnetic water on leaf dry matter percentage in the autumn shown in the same table. The maximum leaf dry matter value $27.20 \%$ in autumn was found from $\mathrm{A}_{1} \mathrm{~B}_{2} \mathrm{C}_{2}$, while the minimum leaf dry matter value $17.79 \%$ was observed from $\mathrm{A}_{2} \mathrm{~B}_{0} \mathrm{C}_{1}$. However, the highest value in the spring (30.46\%) was achieved from $\mathrm{A}_{1} \mathrm{~B}_{1} \mathrm{C}_{2}$ and the lowest value $17.90 \%$ was found from $\mathrm{A}_{2} \mathrm{~B}_{0} \mathrm{C}_{1}$. 


\section{Effect of poultry manure, bio-fertilizers and magnetic water and their interaction on the leaf chlorophyll intensity (spad unit)}

Table 5 shows the significant effect of using poultry manure on the leaf chlorophyll intensity of gladiolus plant var. Cartago. In both seasons, the maximum leaf chlorophyll intensity 58.18, 58.08 spad unit were noticed from $\mathrm{A}_{1}$ treatment, while the minimum leaf chlorophyll intensity 50.53, 47.43 spad unit were achieved from $\mathrm{A}_{2}$ treatment for both seasons respectively.

Table 5. Effect of poultry manure, bio-fertilizers and magnetic water and their interaction on the leaf chlorophyll intensity (spad unit) of gladiolus in two seasons

\begin{tabular}{|c|c|c|c|c|c|c|c|c|c|c|c|c|c|c|c|}
\hline \multicolumn{8}{|c|}{ Autumn } & \multicolumn{8}{|c|}{ Spring } \\
\hline $\mathrm{C}$ & $\mathrm{A}$ & $\mathrm{B}_{0}$ & $\mathrm{~B}_{1}$ & \multicolumn{2}{|c|}{$\mathrm{B}_{2}$} & $A * C$ & $\mathrm{C}$ & & $\mathrm{B}_{0}$ & \multicolumn{2}{|c|}{$\mathrm{B}_{1}$} & $\mathrm{~B}_{2}$ & \multicolumn{2}{|c|}{$A^{*} \mathrm{C}$} & $\mathrm{C}$ \\
\hline \multirow{3}{*}{$\mathrm{C}_{1}$} & $\mathrm{~A}_{0}$ & 42.49 & 50.48 & & .05 & 46.34 & \multirow{3}{*}{$\stackrel{\vec{b}}{\vec{A}}$} & & 43.13 & \multicolumn{2}{|c|}{51.35} & 49.31 & \multicolumn{2}{|c|}{47.93} & \multirow{3}{*}{$\begin{array}{l}\vec{b} \\
\stackrel{t}{A}\end{array}$} \\
\hline & $A_{1}$ & 47.49 & 59.98 & & 35 & 53.94 & & & 48.96 & 60.9 & & 55.95 & 55.2 & & \\
\hline & $\mathrm{A}_{2}$ & 42.20 & 50.71 & & 52 & 47.14 & & & 40.91 & 49.2 & & 42.47 & 44.2 & & \\
\hline \multirow{3}{*}{$\mathrm{C}_{2}$} & $\mathrm{~A}_{0}$ & 50.31 & 64.47 & & 50 & 58.75 & \multirow{3}{*}{$\begin{array}{l}\text { u } \\
\text { w }\end{array}$} & & 49.83 & 60.5 & & 53.70 & 54.6 & & \multirow{3}{*}{$\begin{array}{l}u \\
\ddot{ \pm}\end{array}$} \\
\hline & $\mathrm{A}_{1}$ & 57.02 & 68.83 & & 42 & 62.42 & & & 55.42 & 67.7 & & 59.50 & 60.8 & & \\
\hline & $\mathrm{A}_{2}$ & 50.25 & 58.16 & & 36 & 53.92 & & & 46.81 & 58.1 & & 47.05 & 50.6 & & \\
\hline \multicolumn{8}{|c|}{ Interaction of $\mathrm{B} * \mathrm{C}$} & \multicolumn{8}{|c|}{ Interaction of $\mathrm{B} * \mathrm{C}$} \\
\hline \multicolumn{2}{|c|}{$\mathrm{C} 1$} & 44.06 & 53.72 & \multicolumn{2}{|c|}{49.64} & & & & 44.33 & \multicolumn{2}{|c|}{53.84} & 49.24 & & & \\
\hline \multicolumn{2}{|c|}{$\mathrm{C} 2$} & 52.52 & 63.82 & \multicolumn{2}{|c|}{58.76} & & & & 50.69 & \multicolumn{2}{|c|}{62.13} & 53.42 & & & \\
\hline \multicolumn{6}{|c|}{ Interaction of $\mathrm{A} * \mathrm{~B}$} & \multicolumn{2}{|l|}{ A } & \multicolumn{5}{|c|}{ Interaction of $A * B$} & \multicolumn{3}{|c|}{$\mathrm{A}$} \\
\hline \multicolumn{2}{|c|}{$\mathrm{A}_{0}$} & 46.40 & 57.47 & \multicolumn{2}{|c|}{53.78} & \multicolumn{2}{|c|}{52.55} & & 46.48 & \multicolumn{2}{|c|}{55.93} & 51.51 & \multicolumn{3}{|c|}{51.31} \\
\hline \multicolumn{2}{|c|}{$A_{1}$} & 52.25 & 64.41 & \multicolumn{2}{|c|}{57.89} & 58.1 & & & 52.19 & 64. & & 57.73 & & 58.08 & \\
\hline & & 46.22 & 54.43 & & 94 & 50.5 & & & 43.85 & 53. & & 44.75 & & 47.43 & \\
\hline 1 & & 48.29 & 58.77 & & 20 & & & & 47.51 & 57. & & 51.33 & & & \\
\hline & & & LSD 0. & & & & & & & & LSD & 0.05 & & & \\
\hline $\mathrm{A}$ & $\mathrm{B}$ & $\mathrm{C}$ & $A^{*} B$ & $A * C$ & $\mathrm{~B} * \mathrm{C}$ & \begin{tabular}{l|l}
$\mathrm{C}$ & $\mathrm{A} * \mathrm{~B}$ \\
\end{tabular} & & $\mathrm{~A}$ & $\mathrm{~B}$ & $\mathrm{C}$ & $\mathrm{A} * \mathrm{~B}$ & $A^{*} \mathrm{C}$ & $\mathrm{B} * \mathrm{C}$ & $A^{*}$ & $\mathrm{~B} * \mathrm{C}$ \\
\hline 4.05 & 4.05 & 3.31 & 8.93 & 6.76 & 6.76 & 10.0 & & 2.42 & 2.42 & 1.97 & 5.56 & 5.44 & 5.44 & & 74 \\
\hline
\end{tabular}

A is poultry manure, A0 without poultry manure, A1 application of poultry manure at $2 \%$ of soil weight, A 2 application of poultry manure at $4 \%$ of soil weight. B is bio-fertilizers, B1 is inoculation by bacteria Azospirillum brasilense, B2 is inoculation by bacteria Bacillus subtilis, C is type of irrigation, C1 is irrigation by tap water, $\mathrm{C} 2$ is irrigation by magnetic water

However, the significant effect of using Azospirillum brasilense $\mathrm{B}_{1}$ noticed 58.77, 57.98 spad unit and Bacillus subtilis 54.20, 51.33, was found. These results were significantly differed from control $\mathrm{B}_{0}$ as $48.29,47.51 \mathrm{spad}$ unit was obtained for both seasons respectively.

Irrigation by magnetic water caused increasing of leaf chlorophyll intensity by giving 58.37, 55.41 spad unit for $C_{2}$ as compared to $C_{1}$ which gave 49.14, 49.14 spad unit for both seasons respectively. The interaction of poultry manure, bio-fertilizers and magnetic water had a significant effect on the leaf chlorophyll intensity for both seasons as shown in the same table. The maximum value $68.83,67.71 \mathrm{spad}$ unit were found from $\mathrm{A}_{1} \mathrm{~B}_{1} \mathrm{C}_{2}$, while the minimum value 42.20, 40.91 spad unit were found from $\mathrm{A}_{2} \mathrm{~B}_{0} \mathrm{C}_{1}$. 


\section{Effects of poultry manure, bio-fertilizers magnetic water and their interaction on the Nitrogen (\%) in the leaves}

Table 6 presents the results of application of poultry manure on the nitrogen content in gladiolus leaves and a statistical difference was found in both seasons. It can be noticed that poultry manure at $2 \% \mathrm{~A}_{1}$ recorded highest value $2.52,2.26 \%$, on the other hand, lowest value $1.79,1.76 \%$ were obtained from $\mathrm{A}_{2}$ for two seasons respectively.

Table 6. Effects of poultry manure, bio-fertilizers magnetic water and their interaction on the concentration of Nitrogen (\%) in the leaves of Gladiolus in two seasons

\begin{tabular}{|c|c|c|c|c|c|c|c|c|c|c|c|c|c|c|}
\hline \multicolumn{9}{|c|}{ Autumn } & \multicolumn{6}{|c|}{ Spring } \\
\hline $\mathrm{C}$ & A & $\mathrm{B}_{0}$ & $\mathrm{~B}_{1}$ & & $\mathrm{~B}_{2}$ & $\mathrm{~A} * \mathrm{C}$ & & C & $\mathrm{B}_{0}$ & $\mathrm{~B}_{1}$ & B & 2 & $\mathrm{~A} * \mathrm{C}$ & $\mathrm{C}$ \\
\hline \multirow{3}{*}{$\mathrm{C} 1$} & $\mathrm{~A}_{0}$ & 1.55 & 2.00 & & 1.63 & 1.72 & \multirow{3}{*}{\multicolumn{2}{|c|}{$\dot{\infty}$}} & 1.32 & 1.84 & 1.5 & 54 & 1.57 & \multirow{3}{*}{ ì } \\
\hline & $\mathrm{A}_{1}$ & 1.83 & 2.39 & & 2.06 & 2.09 & & & 1.65 & 1.87 & $1 . \varepsilon$ & 87 & 1.80 & \\
\hline & $\mathrm{A}_{2}$ & 1.48 & 1.95 & & 1.58 & 1.67 & & & 1.27 & 1.78 & 1. & 44 & 1.49 & \\
\hline \multirow{3}{*}{$\mathrm{C} 2$} & $\mathrm{~A}_{0}$ & 1.91 & 2.44 & & 2.06 & 2.13 & \multirow{3}{*}{\multicolumn{2}{|c|}{$\stackrel{N}{w}$}} & 1.81 & 2.49 & 1.5 & 99 & 2.09 & \multirow{3}{*}{$\stackrel{N}{N}$} \\
\hline & $\mathrm{A}_{1}$ & 2.49 & 3.63 & & 2.72 & 2.95 & & & 2.39 & 3.40 & 2.3 & 34 & 2.71 & \\
\hline & $\mathrm{A}_{2}$ & 1.82 & 2.06 & & 1.89 & 1.92 & & & 1.83 & 2.43 & 1.7 & 78 & 2.01 & \\
\hline \multicolumn{9}{|c|}{ Interaction of $\mathrm{B} * \mathrm{C}$} & \multicolumn{6}{|c|}{ Interaction of $\mathrm{B}^{*} \mathrm{C}$} \\
\hline \multicolumn{2}{|c|}{$\mathrm{C} 1$} & 1.62 & 2.11 & \multicolumn{2}{|r|}{1.76} & & & & 1.41 & 1.83 & \multicolumn{2}{|c|}{1.62} & & \\
\hline \multicolumn{2}{|c|}{$\mathrm{C} 2$} & 2.07 & 2.71 & & 2.22 & & & & 2.01 & 2.77 & $2 .($ & 04 & & \\
\hline \multicolumn{6}{|c|}{ Interaction of $\mathrm{A} * \mathrm{~B}$} & \multicolumn{3}{|c|}{ A } & \multicolumn{4}{|c|}{ Interaction of $\mathrm{A} * \mathrm{~B}$} & \multicolumn{2}{|c|}{ A } \\
\hline \multicolumn{2}{|c|}{$\mathrm{A}_{0}$} & 1.73 & 2.22 & & 1.84 & \multicolumn{3}{|c|}{1.93} & 1.57 & 2.17 & 1.7 & 76 & \multicolumn{2}{|c|}{1.83} \\
\hline \multicolumn{2}{|c|}{$\mathrm{A}_{1}$} & 2.16 & 3.01 & & 2.39 & \multicolumn{3}{|c|}{2.52} & 2.02 & 2.64 & 2. & 11 & \multicolumn{2}{|c|}{2.26} \\
\hline \multicolumn{2}{|c|}{$\mathrm{A}_{2}$} & 1.64 & 2.00 & & 1.73 & \multicolumn{3}{|c|}{1.79} & 1.55 & 2.11 & 1. & 61 & \multicolumn{2}{|c|}{1.76} \\
\hline \multicolumn{2}{|c|}{$\mathrm{B}$} & 1.84 & 2.41 & & 1.99 & & & & 1.71 & 2.31 & 1.8 & 83 & & \\
\hline \multicolumn{15}{|c|}{ LSD 0.05} \\
\hline A & B & $\mathrm{C}$ & $A * B$ & $A * C$ & $\mathrm{~B}^{*} \mathrm{C}$ & $A * B$ & & A & B & $\mathrm{C}$ & $A * B$ & $\mathrm{~A}^{*} \mathrm{C}$ & $\mathrm{B} * \mathrm{C}$ & $\mathrm{A} * \mathrm{~B} * \mathrm{C}$ \\
\hline 0.24 & 0.24 & 0.20 & 0.53 & 0.40 & 0.4 & 0.6 & & 0.24 & 0.24 & 0.2 & 0.57 & 0.43 & 0.43 & 0.61 \\
\hline
\end{tabular}

A is poultry manure, A0 without poultry manure, A1 application of poultry manure at $2 \%$ of soil weight, A2 application of poultry manure at $4 \%$ of soil weight. B is bio-fertilizers, B1 is inoculation by bacteria Azospirillum brasilense, B2 is inoculation by bacteria Bacillus subtilis, C is type of irrigation, $\mathrm{C} 1$ is irrigation by tap water, $\mathrm{C} 2$ is irrigation by magnetic water

Inoculated corms with bio-fertilizers were affected significantly on concentration of nitrogen in leaves. The maximum nitrogen concentration $2.41,2.31 \%$ were observed from $\mathrm{B}_{1}$ treatment, while the minimum nitrogen concentration $1.84,1.71 \%$ were noticed from $\mathrm{B}_{0}$ for both seasons respectively. Moreover, the effect of irrigation by magnetic water on nitrogen content in leaves differences significantly was found in two seasons. The highest concentrations $2.33,2.27 \%$ were observed from $\mathrm{C}_{2}$, while the lowest concentrations of nitrogen $1.83,1.62 \%$ were found from both $\mathrm{C}_{1}$ for both seasons respectively.

The interaction between poultry manure, bio-fertilizers and magnetic water on the nitrogen content in gladiolus leaves was statistical difference in both seasons. The maximum values $3.63,3.40 \%$ were achieved from $\mathrm{A}_{1} \mathrm{~B}_{1} \mathrm{C}_{2}$, while the minimum values $1.48,1.27 \%$ were found in both $\mathrm{A}_{2} \mathrm{~B}_{0} \mathrm{C}_{1}$ respectively. 


\section{Effect of poultry manure, bio-fertilizers, magnetic water and their interaction on the concentration of phosphorus $(\%)$ in the leaves}

Table 7 gives the results of application of poultry manure on the phosphorus content in gladiolus leaves var. Cartago and a statistical difference was found in both seasons. The highest phosphorus concentrations $0.31,0.28 \%$ were found from $\mathrm{A}_{1}$, whereas the lowest phosphorus concentrations $0.20,0.18 \%$ were observed from both $\mathrm{A}_{2}$ respectively.

Table 7. Effect of poultry manure, bio-fertilizers, magnetic water and their interaction on the concentration of phosphorus (\%) in the leaves of Gladiolus in two seasons

\begin{tabular}{|c|c|c|c|c|c|c|c|c|c|c|c|c|c|c|c|}
\hline \multicolumn{8}{|c|}{ Autumn } & \multicolumn{8}{|c|}{ Spring } \\
\hline $\mathrm{C}$ & $\mathrm{A}$ & $\mathrm{B}_{0}$ & $\mathrm{~B}_{1}$ & & $\mathrm{~B}_{2}$ & $A * C$ & $\mathrm{C}$ & & $\mathrm{B}_{0}$ & $\mathrm{~B}_{1}$ & & $\mathrm{~B}_{2}$ & $\mathrm{~A} * \mathrm{C}$ & & $\mathrm{C}$ \\
\hline \multirow{3}{*}{$\mathrm{C} 1$} & $\mathrm{~A}_{0}$ & 0.20 & 0.22 & & 0.27 & 0.23 & \multirow{3}{*}{$\stackrel{\circ}{\text { N }}$} & & 0.17 & 0.1 & & 0.24 & 0.20 & & \multirow{3}{*}{ i } \\
\hline & $\mathrm{A}_{1}$ & 0.22 & 0.25 & & 0.28 & 0.25 & & & 0.21 & 0.2 & & 0.24 & 0.23 & & \\
\hline & $\mathrm{A}_{2}$ & 0.15 & 0.19 & & 0.19 & 0.18 & & & 0.15 & 0.1 & & 0.20 & 0.17 & & \\
\hline \multirow{3}{*}{$\mathrm{C} 2$} & $\mathrm{~A}_{0}$ & 0.22 & 0.26 & & 0.30 & 0.26 & \multirow{3}{*}{$\underset{\infty}{\infty}$} & & 0.21 & 0.2 & & 0.28 & 0.2 & & \multirow{3}{*}{ ì } \\
\hline & $\mathrm{A}_{1}$ & 0.30 & 0.37 & & 0.44 & 0.37 & & & 0.28 & 0.3 & & 0.39 & 0.33 & & \\
\hline & $\mathrm{A}_{2}$ & 0.19 & 0.26 & & 0.20 & 0.22 & & & 0.16 & 0.2 & & 0.22 & 0.20 & & \\
\hline \multicolumn{8}{|c|}{ Interaction of $\mathrm{B}^{*} \mathrm{C}$} & \multicolumn{8}{|c|}{ Interaction of $\mathrm{B} * \mathrm{C}$} \\
\hline \multicolumn{2}{|c|}{$\mathrm{C} 1$} & 0.19 & 0.22 & \multicolumn{2}{|r|}{0.25} & & & & 0.18 & \multicolumn{2}{|c|}{0.20} & 0.23 & & & \\
\hline \multicolumn{2}{|c|}{$\mathrm{C} 2$} & 0.24 & 0.30 & & 0.31 & & & & 0.22 & 0.2 & 26 & 0.30 & & & \\
\hline \multicolumn{6}{|c|}{ Interaction of $\mathrm{A}^{*} \mathrm{~B}$} & \multicolumn{2}{|l|}{ A } & \multicolumn{5}{|c|}{ Interaction of $\mathrm{A} * \mathrm{~B}$} & \multicolumn{3}{|c|}{ A } \\
\hline \multicolumn{2}{|c|}{$\mathrm{A}_{0}$} & 0.21 & 0.24 & & 0.29 & \multicolumn{2}{|l|}{0.25} & & 0.19 & \multicolumn{2}{|c|}{0.22} & 0.26 & \multicolumn{3}{|c|}{0.22} \\
\hline \multicolumn{2}{|c|}{$\mathrm{A}_{1}$} & 0.26 & 0.31 & & 0.36 & \multicolumn{2}{|l|}{0.31} & & 0.24 & \multicolumn{2}{|c|}{0.28} & 0.32 & \multicolumn{3}{|c|}{0.28} \\
\hline \multicolumn{2}{|c|}{$\mathrm{A}_{2}$} & 0.17 & 0.22 & & 0.20 & \multicolumn{2}{|l|}{0.20} & & 0.16 & \multicolumn{2}{|c|}{0.19} & 0.21 & \multicolumn{3}{|c|}{0.18} \\
\hline $\mathrm{I}$ & & 0.21 & 0.26 & & 0.28 & & & & 0.20 & 0.2 & 23 & 0.26 & & & \\
\hline & & & LSD 0 & .05 & & & & & & & LSD & 0.05 & & & \\
\hline A & B & $\mathrm{C}$ & $\mathrm{A}^{*} \mathrm{~B}$ & $\mathrm{~A}^{*} \mathrm{C}$ & $B * C$ & $\mathrm{~A} * \mathrm{~B} * \mathrm{C}$ & & A & B & $\mathrm{C}$ & $A * B$ & $A^{*} \mathrm{C}$ & $\mathrm{B} * \mathrm{C}$ & $A^{*}$ & $3 * \mathrm{C}$ \\
\hline 0.02 & 0.02 & 0.01 & 0.06 & 0.05 & 0.05 & 0.05 & & 0.03 & 0.03 & 0.03 & 0.07 & 0.06 & 0.06 & & 09 \\
\hline
\end{tabular}

A is poultry manure, A0 without poultry manure, A1 application of poultry manure at $2 \%$ of soil weight, A2 application of poultry manure at $4 \%$ of soil weight. B is bio-fertilizers, B1 is inoculation by bacteria Azospirillum brasilense, B2 is inoculation by bacteria Bacillus subtilis, C is type of irrigation, $\mathrm{C} 1$ is irrigation by tap water, $\mathrm{C} 2$ is irrigation by magnetic water

Inoculated corms with bio-fertilizers were affected significantly on phosphorus concentration in leaves. The maximum phosphorus concentrations $0.28,0.26 \%$ were observed from $\mathrm{B}_{2}$ inoculation, while the minimum phosphorus concentrations 0.21 , $0.20 \%$ were achieved from control $\mathrm{B}_{0}$ for both seasons respectively. Although the irrigation by magnetic water $\mathrm{C}_{2}$ caused significant differences on phosphorus concentrations $0.28,0.26 \%$, as compared to tap water $\mathrm{C}_{1}$ which gave $0.22,0.20 \%$.

The interaction between poultry manure, bio-fertilizers and magnetic water on the phosphorus content in gladiolus leaves was statistical difference in both seasons. The maximum values $0.44,0.39 \%$ were observed from both $\mathrm{A}_{1} \mathrm{~B}_{2} \mathrm{C}_{2}$, whereas the minimum values $0.15,0.15 \%$ were found from $\mathrm{A}_{2} \mathrm{~B}_{0} \mathrm{C}_{1}$. 


\section{Effect of poultry manure, bio-fertilizers, magnetic water and their interaction on the concentration of potassium (\%) in the leaves}

The data in Table 8 showed the maximum potassium concentrations due to application of poultry manure at $2 \%$ percentage $A_{1}$ which were $3.24,2.95 \%$ significantly differed with $\mathrm{A}_{2}$ resulted $2.55,2.34 \%$ for both seasons respectively. However, the significant effect of bio-fertilizers was noticed with $\mathrm{B}_{1}$ and $\mathrm{B}_{2}$ in two seasons without significant differences between them. The highest potassium concentrations 3.19, 2.99\% were found from both Azospirrilum brasilense $\mathrm{B}_{1}$ followed by Bacillus subtilis $\mathrm{B}_{2}$ which gave 2.92, $2.65 \%$ and the lowest potassium concentrations $2.28,2.12 \%$ were resulted from two control $\mathrm{B}_{0}$ respectively.

Irrigation by magnetic water resulted increasing of potassium concentrations by giving $3.21,2.92 \%$ for $\mathrm{C}_{2}$ as compared to $\mathrm{C}_{1}$ which gave $2.37,2.25 \%$ for both seasons respectively.

The interaction between poultry manure, bio-fertilizers and magnetic water on the potassium content in gladiolus leaves was statistical difference in both seasons. The highest concentrations $4.19,3.81 \%$ were achieved from $\mathrm{A}_{1} \mathrm{~B}_{1} \mathrm{C}_{2}$, while the lowest concentration 1.83, $1.83 \%$ was noticed from both treatments $\mathrm{A}_{2} \mathrm{~B}_{0} \mathrm{C}_{1}$.

Table 8. Effect of poultry manure, bio-fertilizers, magnetic water and their interaction on the concentration of potassium (\%) in the leaves of Gladiolus in two seasons

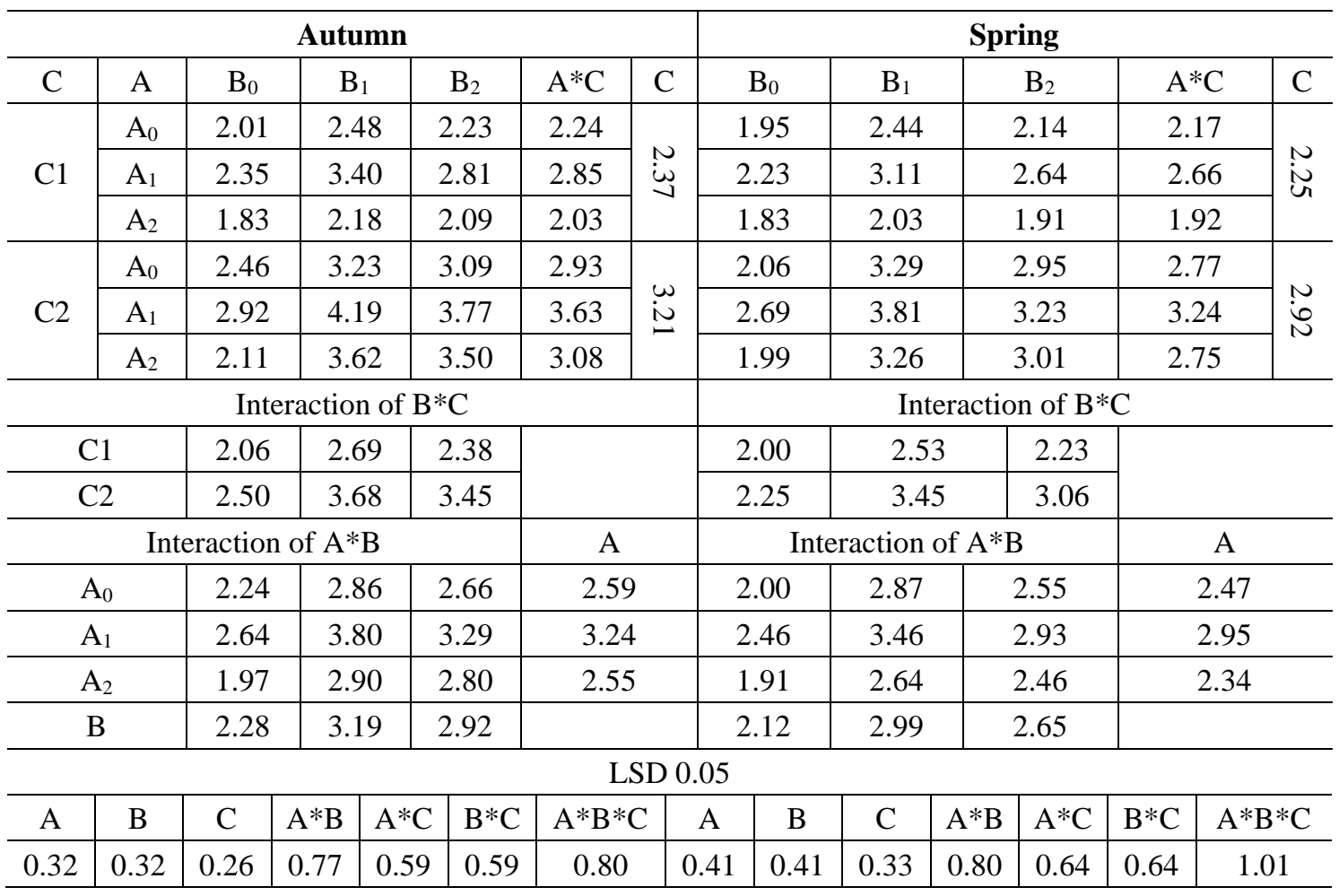

A is poultry manure, A0 without poultry manure, A1 application of poultry manure at $2 \%$ of soil weight, A2 application of poultry manure at $4 \%$ of soil weight. B is bio-fertilizers, B1 is inoculation by bacteria Azospirillum brasilense, B2 is inoculation by bacteria Bacillus subtilis, C is type of irrigation, $\mathrm{C} 1$ is irrigation by tap water, $\mathrm{C} 2$ is irrigation by magnetic water. 


\section{Effect of poultry manure, bio-fertilizers, magnetic water and their interaction on the number of the days for flowering of Gladiolus}

Table 9 shows that the numbers of the days required for flowering for gladiolus var. Cartago were affected significantly by application of poultry manure. The use of $\mathrm{A}_{1}$ resulted of decreasing of the number of the days for flowering 123.95, 84.89 significantly as compared to $\mathrm{A}_{2}$ treatment which flowered after 132.93, 89.19 days for both seasons, respectively. However, the lowest number of the days for flowering affected by inoculations with both bacteria $\mathrm{B}_{1} 125.55,85.25$ days and $\mathrm{B}_{2} 128.28,85.99$ days as compared to control 130.37, 89.96 days for two seasons, respectively.

Irrigation by magnetic water caused decreasing of the number of the days for flowering by giving $125.63,85.33$ days for $\mathrm{C}_{2}$ as compared to $\mathrm{C}_{1}$ which gave $130.50,88.81$ days for two seasons, respectively.

However, the interaction between poultry manure, bio-fertilizers and magnetic water on the number of the days for flowering was found to be significant. In the autumn the minimum numbers of the days required for flowering 120.73, 120.96, 120.99 days were found from $A_{1} B_{0} C_{2}, A_{1} B_{1} C_{2}, A_{1} B_{2} C_{2}$ without any significant differences between them, while all of them differed significantly with control $\mathrm{A}_{0} \mathrm{~B}_{0} \mathrm{C}_{1} 139.18$ days. However, in the spring the lowest number of the days required for flowering 82.11, 83.72 days were obtained from $A_{1} B_{1} C_{2}$ and $A_{1} B_{2} C_{2}$, while the highest number of the days required for flowering 93.83 days was achieved from $\mathrm{A}_{0} \mathrm{~B}_{0} \mathrm{C}_{1}$.

Table 9. Effect of poultry manure, bio-fertilizers, magnetic water and their interaction on the number of the days for flowering of Gladiolus in two seasons

\begin{tabular}{|c|c|c|c|c|c|c|c|c|c|c|c|c|c|c|c|}
\hline \multicolumn{9}{|c|}{ Autumn } & \multicolumn{7}{|c|}{ Spring } \\
\hline $\mathrm{C}$ & $\mathrm{A}$ & $\mathrm{B}_{0}$ & \multicolumn{2}{|c|}{$\mathrm{B}_{1}$} & $\mathrm{~B}_{2}$ & \multicolumn{2}{|c|}{$\mathrm{A}^{*} \mathrm{C}$} & $\mathrm{C}$ & & $\mathrm{B}_{1}$ & $\mathrm{~B}_{2}$ & \multicolumn{2}{|c|}{$\mathrm{A}^{*} \mathrm{C}$} & $\mathrm{C}$ \\
\hline \multirow{3}{*}{$\mathrm{C}_{1}$} & $\mathrm{~A}_{0}$ & 139.18 & \multicolumn{2}{|c|}{118.30} & 133.85 & \multicolumn{2}{|c|}{130.44} & \multirow{3}{*}{$\begin{array}{l}\overrightarrow{0} \\
\dot{0} \\
\dot{0}\end{array}$} & \multicolumn{2}{|c|}{93.83} & 87.44 & 86.28 & \multicolumn{2}{|c|}{89.18} & \multirow{3}{*}{$\begin{array}{l}\infty \\
\infty \\
\infty\end{array}$} \\
\hline & $\mathrm{A}_{1}$ & 129.10 & \multirow{2}{*}{\multicolumn{2}{|c|}{$\begin{array}{l}121.32 \\
132.32\end{array}$}} & 124.61 & \multicolumn{2}{|c|}{127.01} & & \multicolumn{2}{|c|}{88.72} & 84.89 & 83.22 & \multicolumn{2}{|c|}{85.61} & \\
\hline & $\mathrm{A}_{2}$ & 134.47 & & & 135.33 & 134.0 & & & \multicolumn{2}{|c|}{93.89} & 88.33 & 92.67 & \multicolumn{2}{|c|}{91.63} & \\
\hline \multirow{3}{*}{$\mathrm{C}_{2}$} & $\mathrm{~A}_{0}$ & 127.27 & \multicolumn{2}{|c|}{122.67} & 122.67 & 124.2 & & \multirow{3}{*}{$\begin{array}{l}\bar{N} \\
\dot{\omega} \\
\dot{\omega}\end{array}$} & \multicolumn{2}{|c|}{88.21} & 83.22 & 83.77 & & 35.07 & \\
\hline & $\mathrm{A}_{1}$ & 120.73 & 120 & .96 & 120.99 & 120.8 & & & & 6.66 & 82.11 & 83.72 & & 34.16 & is \\
\hline & $\mathrm{A}_{2}$ & 131.48 & 13 & .72 & 132.23 & 131.8 & & & & .44 & 85.53 & 86.27 & & 36.75 & \\
\hline & & & Intera & ction of & $\mathrm{B}^{*} \mathrm{C}$ & & & & & & Interac & tion of $\mathrm{F}$ & $\mathrm{B} * \mathrm{C}$ & & \\
\hline $\mathrm{C}_{1}$ & 1 & 134.25 & 132 & .64 & 131.26 & & & & & 92.15 & & 6.89 & 87.39 & & \\
\hline $\mathrm{C}_{2}$ & 2 & 126.49 & 125 & .12 & 125.30 & & & & & 87.77 & & 3.62 & 84.59 & & \\
\hline & & Interac & of of & $A * B$ & & & A & & & Interac & ction of & $A * B$ & & A & \\
\hline $\mathrm{A}_{0}$ & 0 & 133.22 & 120 & .49 & 128.26 & & 7.32 & & & .02 & 85.33 & 85.03 & & 87.13 & \\
\hline $\mathrm{A}_{1}$ & 1 & 124.92 & 12 & .14 & 122.80 & & 3.95 & & & .69 & 83.50 & 83.47 & & 84.89 & \\
\hline $\mathrm{A}_{2}$ & 2 & 132.98 & 132 & .02 & 133.78 & & 2.93 & & & .16 & 86.93 & 89.47 & & 89.19 & \\
\hline $\mathrm{B}$ & 3 & 130.37 & 125 & .55 & 128.28 & & & & & .96 & 85.25 & 85.99 & & & \\
\hline & & & & SD 0.0 & & & & & & & & D 0.05 & & & \\
\hline $\mathrm{A}$ & $\mathrm{B}$ & $\mathrm{C}$ & $\mathrm{A} * \mathrm{~B}$ & $\mathrm{~A}^{*} \mathrm{C}$ & $\mathrm{B} * \mathrm{C}$ & $A * B * C$ & $\mathrm{~A}$ & & $\mathrm{~B}$ & $\mathrm{C}$ & $\mathrm{A} * \mathrm{~B}$ & $\mathrm{~A} * \mathrm{C}$ & $\mathrm{B} * \mathrm{C}$ & $\mathrm{A} * \mathrm{~B}$ & \\
\hline 1.23 & 1.23 & 1.01 & 5.86 & 2.21 & 4.93 & 3.01 & 1.6 & & 1.69 & 1.38 & 3.64 & 3.09 & 2.96 & 4.0 & \\
\hline
\end{tabular}

A is poultry manure, A0 without poultry manure, A1 application of poultry manure at $2 \%$ of soil weight, A 2 application of poultry manure at $4 \%$ of soil weight. B is bio-fertilizers, B1 is inoculation by bacteria Azospirillum brasilense, B2 is inoculation by bacteria Bacillus subtilis, $\mathrm{C}$ is type of irrigation, $\mathrm{C} 1$ is irrigation by tap water, $\mathrm{C} 2$ is irrigation by magnetic water 


\section{Effect poultry manure, of bio-fertilizers, magnetic water and their interaction on the}

\section{anthocyanin concentration in flower petals $\left(\mathrm{mg}^{100} \mathrm{~g}^{-1}\right)$ of gladiolus}

Table 10 explains that poultry manure applications A had significant effect on the anthocyanin concentration in flower petals of gladiolus var. Cartago. The highest concentrations $21.99,19.27 \mathrm{mg}$. $100 \mathrm{~g}^{-1}$ were found from $\mathrm{A}_{1}$, whereas the lowest concentrations $15.93,13.40 \mathrm{mg} .100 \mathrm{~g}^{-1}$ were obtained from $\mathrm{A}_{2}$ for both seasons respectively.

Table 10. Effect poultry manure, of bio-fertilizers, magnetic water and their interaction on the anthocyanin concentration in flower petals $\left(\mathrm{mg} .100 \mathrm{~g}^{-1}\right)$ of gladiolus in two seasons

\begin{tabular}{|c|c|c|c|c|c|c|c|c|c|c|c|c|c|c|}
\hline \multicolumn{8}{|c|}{ Autumn } & \multicolumn{7}{|c|}{ Spring } \\
\hline $\mathrm{C}$ & A & $\mathrm{B}_{0}$ & & $\mathrm{~B}_{1}$ & $\mathrm{~B}_{2}$ & $\mathrm{~A} * \mathrm{C}$ & $\mathrm{C}$ & $\mathrm{B}_{0}$ & & $\mathrm{~B}_{1}$ & $\mathrm{~B}_{2}$ & & $* \mathrm{C}$ & $\mathrm{C}$ \\
\hline \multirow{3}{*}{$\mathrm{C}_{1}$} & $\mathrm{~A}_{0}$ & 14.96 & & 6.60 & 20.87 & 17.48 & \multirow{3}{*}{$\begin{array}{l}\bar{v} \\
\dot{8}\end{array}$} & 11.62 & & 1.77 & 12.36 & & .92 & \multirow{3}{*}{ 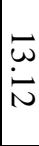 } \\
\hline & $\mathrm{A}_{1}$ & 18.82 & & 1.73 & 23.49 & 21.35 & & 14.57 & & 6.38 & 19.17 & & .70 & \\
\hline & $\mathrm{A}_{2}$ & 13.94 & & 5.58 & 15.09 & 14.87 & & 9.46 & & 0.93 & 11.84 & & .74 & \\
\hline \multirow{3}{*}{$\mathrm{C}_{2}$} & $\mathrm{~A}_{0}$ & 16.56 & & 9.19 & 20.86 & 18.87 & \multirow{3}{*}{$\begin{array}{l}\overrightarrow{0} \\
\text { ui }\end{array}$} & 15.23 & & 9.78 & 21.81 & & .94 & \multirow{3}{*}{ 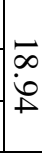 } \\
\hline & $\mathrm{A}_{1}$ & 20.26 & & 2.10 & 25.53 & 22.63 & & 18.58 & & 2.17 & 24.76 & & .83 & \\
\hline & $\mathrm{A}_{2}$ & 16.34 & & 7.60 & 17.03 & 16.99 & & 13.65 & & 7.29 & 17.24 & & .06 & \\
\hline \multicolumn{8}{|c|}{ Interaction of $\mathrm{B}^{*} \mathrm{C}$} & \multicolumn{7}{|c|}{ Interaction of $\mathrm{B}^{*} \mathrm{C}$} \\
\hline \multicolumn{2}{|c|}{$\mathrm{C}_{1}$} & 15.90 & \multicolumn{2}{|c|}{17.97} & 19.82 & & & 11.88 & \multicolumn{2}{|c|}{13.03} & 14.46 & & & \\
\hline \multicolumn{2}{|c|}{$\mathrm{C}_{2}$} & 17.72 & & 9.63 & 21.15 & & & 15.82 & & .75 & 21.27 & & & \\
\hline \multicolumn{6}{|c|}{ Interaction of $\mathrm{A} * \mathrm{~B}$} & \multicolumn{2}{|l|}{ A } & \multicolumn{4}{|c|}{ Interaction of $\mathrm{A} * \mathrm{~B}$} & \multicolumn{3}{|c|}{ A } \\
\hline \multicolumn{2}{|c|}{$\mathrm{A}_{0}$} & 15.76 & \multicolumn{2}{|c|}{17.89} & 20.87 & \multicolumn{2}{|c|}{17.93} & \multicolumn{2}{|c|}{13.42} & 15.78 & 17.09 & \multicolumn{3}{|c|}{15.43} \\
\hline \multicolumn{2}{|c|}{$\mathrm{A}_{1}$} & 19.54 & \multicolumn{2}{|c|}{21.92} & 24.51 & \multicolumn{2}{|c|}{21.99} & \multicolumn{2}{|c|}{16.57} & 19.28 & 21.97 & & 19.27 & \\
\hline & & 15.14 & & 6.59 & 16.06 & 15.93 & & 11.55 & & 14.11 & 14.54 & & 13.40 & \\
\hline & & 16.81 & & 8.80 & 20.48 & & & 13.85 & & 16.39 & 17.87 & & & \\
\hline & & & & D 0.05 & & & & & & LSD & 0.05 & & & \\
\hline $\mathrm{A}$ & $\mathrm{B}$ & $\mathrm{C}$ & $A * B$ & $A * C$ & $\mathrm{~B} * \mathrm{C}$ & $\mathrm{A} * \mathrm{~B} * \mathrm{C}$ & A & $\mathrm{B}$ & $\mathrm{C}$ & $A * B$ & $A * C$ & $\mathrm{~B} * \mathrm{C}$ & $A * B$ & $3 * \mathrm{C}$ \\
\hline 1.20 & 1.2 & 0.97 & 2.26 & 2.24 & 3.11 & 3.05 & 1.82 & 1.82 & 1.49 & 4.88 & 2.96 & 2.96 & 4.5 & \\
\hline
\end{tabular}

A is poultry manure, A0 without poultry manure, A1 application of poultry manure at $2 \%$ of soil weight, A2 application of poultry manure at $4 \%$ of soil weight. B is bio-fertilizers, B1 is inoculation by bacteria Azospirillum brasilense, B2 is inoculation by bacteria Bacillus subtilis, C is type of irrigation, C1 is irrigation by tap water, $\mathrm{C} 2$ is irrigation by magnetic water

Also, the significant effect of bio-fertilizers on anthocyanin concentration in flower petals was shown in the same table. In the autumn the maximum value $20.48 \mathrm{mg} .100 \mathrm{~g}^{-}$ ${ }^{1}$ due to inoculation by $B_{2}$, while the minimum value $16.81 \mathrm{mg} .100 \mathrm{~g}^{-1}$ was found from control. In the spring there were not significant differences between inoculations of $\mathrm{B}_{1}$ and $\mathrm{B}_{2}$ which gave $16.39,17.87 \mathrm{mg} .100 \mathrm{~g}^{-1}$ whereas both of them differed significantly with control $13.85 \mathrm{mg} .100 \mathrm{~g}^{-1}$.

Irrigation by magnetic water $\mathrm{C}_{2}$ caused increasing of anthocyanin concentration in flower petals which gave $19.50,18.94 \mathrm{mg} .100 \mathrm{~g}^{-1}$ as compared to irrigation by tap water $\mathrm{C}_{1}$ which achieved $17.90,13.12 \mathrm{mg} .100 \mathrm{~g}^{-1}$ for both seasons, respectively.

However, the interaction between poultry manure, bio-fertilizers and magnetic water on the anthocyanin concentration in flower petals had significant differences. In the autumn the highest concentration $25.53 \mathrm{mg} .100 \mathrm{~g}^{-1}$ was noticed from $\mathrm{A}_{1} \mathrm{~B}_{2} \mathrm{C}_{2}$ followed 
by $\mathrm{A}_{1} \mathrm{~B}_{2} \mathrm{C}_{1}$ which gave $23.49 \mathrm{mg} .100 \mathrm{~g}^{-1}$, while the lowest concentration $13.94 \mathrm{mg} .100 \mathrm{~g}^{-}$ 1 was achieved from $\mathrm{A}_{2} \mathrm{~B}_{0} \mathrm{C}_{1}$. Also, the interaction of three study factor affected

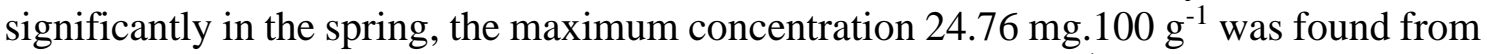
$\mathrm{A}_{1} \mathrm{~B}_{2} \mathrm{C}_{2}$ followed by $\mathrm{A}_{1} \mathrm{~B}_{1} \mathrm{C}_{2}$ which gave $22.17 \mathrm{mg} .100 \mathrm{~g}^{-1}$ while the minimum concentration $9.4617 \mathrm{mg} .100 \mathrm{~g}^{-1}$ was obtained from $\mathrm{A}_{2} \mathrm{~B}_{0} \mathrm{C}_{1}$.

\section{Effect of poultry manure, bio-fertilizers, magnetic water and their interaction on the basal floral diameter (cm) of gladiolus}

Results shown in Table 11 indicates that the application of $\mathrm{A}_{1}$ gave highest values in two seasons $12.16,10.44 \mathrm{~cm}$ were noticed from both $A_{1}$, while the lowest values $8.76,8.86 \mathrm{~cm}$ were obtained from both $\mathrm{A}_{2}$ respectively. Moreover, the floral diameter was affected significantly by inoculations the corms by $\mathrm{B}_{1}$ and $\mathrm{B}_{2}$. The maximum floral diameter 11.33, $10.32 \mathrm{~cm}$ were found from $B_{1}$ followed by $B_{2}$ which gave $11.09,9.97 \mathrm{~cm}$ those two treatments varied significantly with both control $9.07,8.23 \mathrm{~cm}$ for two seasons respectively.

The irrigation by $\mathrm{C}_{2}$ caused increasing in floral diameter in two seasons by giving 11.01, $10.17 \mathrm{~cm}$ were found from $C_{2}$ as compared to $C_{1}$ which gave $9.89,8.84 \mathrm{~cm}$ respectively. However, the interaction between poultry manure, bio-fertilizers and magnetic water gave statistical differences on lower floral diameter. The highest values in the autumn 13.73, 13.54, $13.01 \mathrm{~cm}$ were obtained from $\mathrm{A}_{1} \mathrm{~B}_{2} \mathrm{C}_{2}, \mathrm{~A}_{1} \mathrm{~B}_{1} \mathrm{C}_{2}, \mathrm{~A}_{1} \mathrm{~B}_{2} \mathrm{C}_{1}$, while the lowest value $7.58 \mathrm{~cm}$ was noticed from $\mathrm{A}_{2} \mathrm{~B}_{0} \mathrm{C}_{1}$. In the spring the maximum floral diameter $12.19,11.99 \mathrm{~cm}$ were obtained from $A_{1} B_{1} C_{2}, A_{1} B_{2} C_{2}$, whereas the minimum floral diameter $6.96 \mathrm{~cm}$ was found from $\mathrm{A}_{2} \mathrm{~B}_{0} \mathrm{C}_{1}$.

Table 11. Effect of poultry manure, bio-fertilizers, magnetic water and their interaction on the basal floral diameter $(\mathrm{cm})$ of gladiolus in two seasons in two seasons

\begin{tabular}{|c|c|c|c|c|c|c|c|c|c|c|c|c|c|c|}
\hline \multicolumn{8}{|c|}{ Autumn } & \multicolumn{7}{|c|}{ Spring } \\
\hline $\mathrm{C}$ & $\mathrm{A}$ & $\mathrm{B}_{0}$ & $\mathrm{~B}_{1}$ & & $\mathrm{~B}_{2}$ & $\mathrm{~A}^{*} \mathrm{C}$ & $\mathrm{C}$ & $\mathrm{B}_{0}$ & \multicolumn{2}{|c|}{$\mathrm{B}_{1}$} & $\mathrm{~B}_{2}$ & & $\mathrm{~A}^{*} \mathrm{C}$ & $\mathrm{C}$ \\
\hline \multirow{3}{*}{$\mathrm{C}_{1}$} & $\mathrm{~A}_{0}$ & 8.34 & 10.54 & & 10.29 & 9.72 & \multirow{3}{*}{$\begin{array}{l}0 \\
\infty \\
0\end{array}$} & 7.88 & \multicolumn{2}{|c|}{9.02} & 8.3 & & 8.42 & \multirow{3}{*}{$\begin{array}{l}\infty \\
\infty \\
+\end{array}$} \\
\hline & $\mathrm{A}_{1}$ & 9.76 & 12.03 & & 13.01 & 11.60 & & 8.80 & \multicolumn{2}{|c|}{10.01} & 10.4 & & 9.76 & \\
\hline & $\mathrm{A}_{2}$ & 7.58 & 9.34 & & 8.13 & 8.35 & & 6.96 & \multicolumn{2}{|c|}{9.10} & 8.9 & & 8.33 & \\
\hline \multirow{3}{*}{$\mathrm{C}_{2}$} & $\mathrm{~A}_{0}$ & 9.97 & 12.11 & & 12.17 & 11.42 & \multirow{3}{*}{$\stackrel{\check{0}}{\circ}$} & 8.27 & \multicolumn{2}{|c|}{11.28} & 10.4 & & 10.01 & \multirow{3}{*}{$\ddot{v}$} \\
\hline & $\mathrm{A}_{1}$ & 10.89 & 13.54 & & 13.73 & 12.72 & & 9.16 & \multicolumn{2}{|c|}{12.19} & 11.9 & & 11.11 & \\
\hline & $\mathrm{A}_{2}$ & 7.88 & 10.39 & & 9.20 & 9.16 & & 8.30 & \multicolumn{2}{|c|}{10.30} & 9.5 & & 9.39 & \\
\hline \multicolumn{8}{|c|}{ Interaction of $\mathrm{B} * \mathrm{C}$} & \multicolumn{7}{|c|}{ Interaction of $\mathrm{B} * \mathrm{C}$} \\
\hline \multicolumn{2}{|c|}{$\mathrm{C}_{1}$} & 8.56 & \multicolumn{2}{|c|}{10.64} & \multirow{2}{*}{\begin{tabular}{|l|}
10.48 \\
11.70
\end{tabular}} & & & \multicolumn{2}{|c|}{7.88} & \multicolumn{2}{|c|}{\begin{tabular}{l|l}
9.38 & \\
\end{tabular}} & \multicolumn{2}{|l|}{9.25} & \\
\hline \multicolumn{2}{|c|}{$\mathrm{C}_{2}$} & 9.58 & 12. & & & & & 8.58 & & 11. & & 10.68 & & \\
\hline & & Interact & of $\mathrm{A}$ & & & $\mathrm{A}$ & & & ntera & tion of & & & & $\mathrm{A}$ \\
\hline $\mathrm{A}_{0}$ & & 9.16 & 11. & & 11.23 & 10.57 & & 8.07 & & 10.15 & & 9.42 & & 21 \\
\hline $\mathrm{A}_{1}$ & & 10.33 & 12. & & 13.37 & 12.16 & & 8.98 & & 11.10 & & 11.23 & & .44 \\
\hline $\mathrm{A}_{2}$ & & 7.73 & 9.8 & & 8.67 & 8.76 & & 7.63 & & 9.70 & & 9.25 & & 86 \\
\hline $\mathrm{B}$ & & 9.07 & 11. & & 11.09 & & & 8.23 & & 10.32 & & 9.97 & & \\
\hline & & & & & & LSD & 0.05 & & & & & & & \\
\hline $\mathrm{A}$ & $\mathrm{B}$ & $\mathrm{C}$ & $\mathrm{A} * \mathrm{~B}$ & $\mathrm{~A} * \mathrm{C}$ & $\mathrm{B} * \mathrm{C}$ & $\mathrm{A} * \mathrm{~B} * \mathrm{C}$ & $\mathrm{A}$ & $\mathrm{B}$ & $\mathrm{C}$ & $\mathrm{A} * \mathrm{~B}$ & $A * C$ & $\mathrm{~B} * \mathrm{C}$ & A*1 & $3 * \mathrm{C}$ \\
\hline 1.02 & 1.02 & \begin{tabular}{l|l}
2 & 0.84 \\
\end{tabular} & 1.79 & 1.68 & 1.68 & 2.54 & 0.98 & 0.98 & 0.80 & 1.77 & 1.39 & 1.39 & & 36 \\
\hline
\end{tabular}

$\mathrm{A}$ is poultry manure, A0 without poultry manure, A1 application of poultry manure at $2 \%$ of soil weight, A2 application of poultry manure at $4 \%$ of soil weight. B is bio-fertilizers, B1 is inoculation by bacteria Azospirillum brasilense, B2 is inoculation by bacteria Bacillus subtilis, C is type of irrigation, C1 is irrigation by tap water, $\mathrm{C} 2$ is irrigation by magnetic water 


\section{Effect of poultry manure, bio-fertilizers, magnetic water and their interaction on the vase life (day) in magnetic water of gladiolus}

The effect of poultry manure on the number of the days for vase life of gladiolus var. Cartago is shown in Table 12. The highest number of the days 12.12, 9.83 day were noticed from $A_{1}$ application for both seasons, while the lowest number of the day 8.88 day in the autumn was obtained from $\mathrm{A}_{2}$ application and 8.18 day in the spring was noticed from $\mathrm{A}_{0}$.

However, the inoculation of gladiolus corms with bio-fertilizers significantly affected flowers vase life. The highest vase lives $11.04,10.45$ days were obtained with $\mathrm{B}_{2}, \mathrm{~B}_{1}$ inoculation in the autumn respectively, whereas the lowest vase life 8.85 day was found from $\mathrm{B}_{0}$. In the spring the highest vase lives 9.62, 9.54 days were found from $\mathrm{B}_{1}, \mathrm{~B}_{2}$, while the lowest vase lives 7.66 days was achieved from $\mathrm{B}_{0}$. The irrigation by magnetic water caused increasing of vase life significantly. The $11.05,9.35$ day achieved from $\mathrm{C}_{2}$ as compared to $\mathrm{C}_{1}$ which gave $9.17,8.53$ day for both seasons, respectively.

Table 12. Effect of poultry manure, bio-fertilizers, magnetic water and their interaction on the vase life (day) in magnetic water of gladiolus in two seasons

\begin{tabular}{|c|c|c|c|c|c|c|c|c|c|c|c|c|c|c|}
\hline \multicolumn{8}{|c|}{ Autumn } & \multicolumn{7}{|c|}{ Spring } \\
\hline $\mathrm{C}$ & $\mathrm{A}$ & $\mathrm{B}_{0}$ & $\mathrm{~B}_{1}$ & \multicolumn{2}{|r|}{$\mathrm{B}_{2}$} & $\mathrm{~A}^{*} \mathrm{C}$ & $\mathrm{C}$ & $\mathrm{B}_{0}$ & \multicolumn{2}{|l|}{$\mathrm{B}_{1}$} & $\mathrm{~B}_{2}$ & \multicolumn{2}{|r|}{$A^{*} \mathrm{C}$} & $\mathrm{C}$ \\
\hline \multirow{3}{*}{$\mathrm{C}_{1}$} & $\mathrm{~A}_{0}$ & 7.13 & 8.42 & & 9.90 & 8.48 & \multirow{3}{*}{$\stackrel{\bullet}{\forall}$} & 6.99 & \multicolumn{2}{|c|}{8.17} & 8.53 & \multicolumn{2}{|r|}{7.90} & \multirow{3}{*}{$\underset{\omega}{\infty}$} \\
\hline & $\mathrm{A}_{1}$ & 9.62 & 11.22 & & 1.85 & 10.90 & & 7.50 & \multicolumn{2}{|c|}{9.89} & 9.55 & \multicolumn{2}{|r|}{8.98} & \\
\hline & $\mathrm{A}_{2}$ & 6.58 & 8.66 & & .11 & 8.12 & & 7.41 & \multicolumn{2}{|c|}{9.22} & 9.50 & \multicolumn{2}{|r|}{8.71} & \\
\hline \multirow{3}{*}{$\mathrm{C}_{2}$} & $\mathrm{~A}_{0}$ & 8.97 & 10.15 & & 1.44 & 10.19 & \multirow{3}{*}{ 云 } & 7.44 & \multicolumn{2}{|c|}{9.28} & 8.66 & \multicolumn{2}{|r|}{8.46} & \multirow{3}{*}{ U } \\
\hline & $\mathrm{A}_{1}$ & 11.89 & 13.89 & & 4.22 & 13.33 & & 9.11 & \multicolumn{2}{|c|}{11.39} & 11.55 & \multicolumn{2}{|c|}{10.68} & \\
\hline & $\mathrm{A}_{2}$ & 8.89 & 10.33 & & 9.67 & 9.63 & & 7.52 & \multicolumn{2}{|c|}{9.77} & 9.44 & \multicolumn{2}{|c|}{8.91} & \\
\hline \multicolumn{8}{|c|}{ Interaction of $\mathrm{B} * \mathrm{C}$} & \multicolumn{7}{|c|}{ Interaction of $\mathrm{B} * \mathrm{C}$} \\
\hline \multicolumn{2}{|c|}{$\mathrm{C}_{1}$} & 7.78 & 9.43 & \multicolumn{2}{|c|}{10.29} & & & 7.30 & \multicolumn{2}{|c|}{9.09} & 9.19 & & & \\
\hline \multicolumn{2}{|c|}{$\mathrm{C}_{2}$} & 9.92 & 11.46 & & 1.78 & & & 8.02 & 10 & & 9.88 & & & \\
\hline & & nteractic & of $A^{*}$ & & & A & & & teracti & n of & $* \mathrm{~B}$ & & A & \\
\hline $\mathrm{A}_{\mathrm{c}}$ & & 8.05 & 9.29 & & 0.67 & 9.34 & & 7.22 & & & 8.60 & & 8.18 & \\
\hline $\mathrm{A}_{1}$ & & 10.76 & 12.55 & & 3.03 & 12.12 & & 8.31 & & 64 & 10.55 & & 9.83 & \\
\hline $\mathrm{A}_{2}$ & & 7.73 & 9.49 & & 9.39 & 8.88 & & 7.47 & & 50 & 9.47 & & 8.81 & \\
\hline B & & 8.85 & 10.45 & & 1.04 & & & 7.66 & & 52 & 9.54 & & & \\
\hline & & & & & & LSD & 0.05 & & & & & & & \\
\hline A & B & $\mathrm{C}$ & $A * B$ & $\mathrm{~A}^{*} \mathrm{C}$ & $\mathrm{B} * \mathrm{C}$ & $\mathrm{A} * \mathrm{~B} * \mathrm{C}$ & A & B & $\mathrm{C}$ & $A * B$ & $A * C$ & $\mathrm{~B} * \mathrm{C}$ & $\mathrm{A} * \mathrm{~B}$ & \\
\hline 0.56 & 0.56 & 0.45 & 1.55 & 1.22 & 1.22 & 1.39 & 0.65 & 0.65 & 0.53 & 1.22 & 1.12 & 1.12 & $1 .($ & \\
\hline
\end{tabular}

$\mathrm{A}$ is poultry manure, A0 without poultry manure, A1 application of poultry manure at $2 \%$ of soil weight, A 2 application of poultry manure at $4 \%$ of soil weight. B is bio-fertilizers, B1 is inoculation by bacteria Azospirillum brasilense, B2 is inoculation by bacteria Bacillus subtilis, C is type of irrigation, $\mathrm{C} 1$ is irrigation by tap water, $\mathrm{C} 2$ is irrigation by magnetic water

However, the interaction between $\mathrm{A}, \mathrm{B}$ and $\mathrm{C}$ gave statistical differences on vase life in both seasons. The highest vase life 14.22, 11.55 days were found from $\mathrm{A}_{1} \mathrm{~B}_{2} \mathrm{C}_{2}$ followed by $\mathrm{A}_{1} \mathrm{~B}_{1} \mathrm{C}_{2}$ which amounted $13.89,11.39$ days for both seasons respectively, while the lowest vase life 6.58day was recorded from $\mathrm{A}_{2} \mathrm{~B}_{0} \mathrm{C}_{1}$ for autumn season, and 6.99 day was noticed from $\mathrm{A}_{0} \mathrm{~B}_{0} \mathrm{C}_{1}$ for spring season. 


\section{Discussion}

The reason for the difference of plant height in autumn and spring seasons Table 3 might be that clay percentage in soil media $A_{1}$ is 37.6 compared to soil media $A_{2}$ is 21.6 as it is shown in Table 1. This effect may be attributed to the physical properties of some ions adhere on the clay soil particles (Mazhar, 2010).

Regarding the inoculation of gladiolus corms with bacteria Azospirillum brasilense, it gave the maximum plant height and there were not significant differences with inoculation by Bacillus subtilis, while both of them are different from treatment without bacteria. This result is similar to what was obtained by Ali et al. (2014) as they reported that the vegetative growth improved after the application of bacteria Azospirillum. Moreover, a significant difference in vegetative growth was observed after using Azotobacter and Phosphate Solubilizing Bacteria (PSB) on growth of gladiolus by Srivastava and Govil (2005). Using magnetic water can improve plant height as it increases the ability of soil to get rid of salt, and it helps to better assimilate nutrients in plants during vegetative growth.

In this study, dry matter percentage in Gladiolus leaves were significantly affected by the application of $2 \%$ poultry manure in soil media (Table 4). These results could be due to efficient nitrogen availability which led to the improvement of vegetative growth (Shah et al., 2016). Nitrogen as an essential component of protein, nucleic acid and many important substances like chlorophyll, which are required for vegetative growth and might be responsible for the increase in dry matter accumulation in leaves. The soil bacteria belonging to the genera Bacillus is more common. The major microbiological means by which insoluble phosphorus compounds are mobilized by the production of organic acids, accompanied by acidification of the medium. The organic and inorganic acids convert tricalcium phosphate to di- and monobasic phosphates with the net result of an enhanced availability of the element to the plant (Yazdani et al., 2009).

The magnetic field can increase ions mobility and ions uptake which leads to a better photo stimulation and growth (Pietruszewski, 1999). Moreover, magnetic field has the ability to change water properties. Thus, this results in the increase of chlorophyll content which leads to increase in fresh weight of leaves and might cause nutrient accumulation in the leaves.

Effects of the interaction $\mathrm{A}_{1} \mathrm{~B}_{1} \mathrm{C}_{2}$ on chlorophyll intensity might be due to effects of each factor on all vegetative growth characteristics of Gladiolus var. Cartago, and it was clearly compact with the high concentration of nitrogen in leaves for both seasons 3.63, $3.40 \%$ that is shown in Table 6, which had major role of increasing photochemical reduction. These results are close with findings of Al-Khazan et al. (2011) that noticed that photosynthetic pigment and nutrient content of Simmondsia chinensis L. enhanced when irrigated by magnetic water. Atak et al. (1997) suggested that the increase of photosynthetic pigments was due to an increase in cytokinin synthesis and this plays an important role on chloroplast development. Magnetic fields are known to induce biochemical changes and affect photo pigments (Dhawi and Al-Khayri, 2009).

Tables 6-8 illustrated that $\mathrm{A}_{1}$ had significant effect on nutrient concentration in leaves of gladiolus. This may be due to poultry manure which is an excellent organic fertilizer, as it contains high nitrogen, phosphorus, potassium and other essential nutrients (Garg and Bahl, 2008). The addition of organic fertilizers gives the plant an opportunity to provide more efficiently in the nutrients needed by nitrogen that enters into the composition of a number of important organic compounds in the biological processes in 
the plant. It also involves into the synthesis of nucleic acids such as DNA, RNA and helps the building of important proteins that increase division and elongation of cells.

Although, the inoculation corms of Gladiolus var. Cartago by each Azospirrilum brasilense and Bacillus subtilis had significant differences in nutrient content in leaves as compared to treatment with control. These results are accordance with (Orhan et al., 2006) who investigated two Bacillus strains OSU-142 (N2-fixing) and M3 (N2-fixing and phosphate solubilizing) that were tested alone or in combinations on organically grown primo cane fruiting raspberry (cv. Heritage). It was found that bacterial treatment improves nutrient uptake and increase most nutrient element contents $\mathrm{P}, \mathrm{Ca}, \mathrm{Fe}, \mathrm{Mn}$ and $\mathrm{K}$ in leaves.

Third factor that caused of increasing nutrient element concentration in leaves was irrigation by magnetic water. These results agree with findings of Al-Ma athidi (2006) who investigated the effect of magnetic water on Gerbera jamessonii which caused to increasing of nitrogen and magnesium availability in soil solution (Hashemabadi et al., 2015; Abdelaziz and Abdelrazig, 2014).

As indicated in Tables 9-12, treatment $A_{1}$ had significant effects on most flower characterizes (Number of the days for flowering, anthocyanin concentration in petals, basal floral diameter and vase life) of gladiolus var. Cartago. The results were on line with Jha (2011) findings that the farm yard manure $10 \mathrm{t}^{\mathrm{h}} \mathrm{ha}^{-1}$ with $75 \%$ RDF gave significant effect on the reducing the number of the days for spike emergence of gladiolus cultivar candyam. In this study, the use of $4 \%$ did not have significant effects on the flower attributes which may be because of effects of high Electrical conductivity of $\mathrm{A}_{2}$ which 2.91 was higher than $A_{1} 1.70$ which might be due to the presence of more salts in the poultry manure at the rate $\mathrm{A}_{2}$ as shown in Table 1.

The bio-fertilizers inoculation gave significant effects on most flowering characterizes as compared to control. The data in Table 9 indicated that the number of the days required to opening of basal floret was significantly reduced with the inoculation of Azospirillum barasilense and Bacillus subtilis in two seasons. These results were in close with findings of Singh (2009). The study was carried out to use bio-fertilizers in combination with nitrogen on growth and flowering of Gladiolus, to see the effect of Bacillus and Pseudomonas strains on growth and flowering of gladiolus cultivar American Beauty. Significant increase in spike length, and number of florets per spike and floret diameter was recorded under levels of nitrogen, bio-fertilizers, Bacillus, Pseudomonas strains and their combinations.

Moreover, irrigation by magnetic water caused improvements in flower quality. The reason for the positive effects of magnetized water could be due to the fact that the magnetic field is dependent on changes in the physical and chemical properties of water, including reducing surface tension, viscosity and water density, making it lighter and easier to absorb. The results were close with findings of Al-Maathidi (2006) in the study of using magnetized water on Gerbera jamesonii.

Regarding of vase life, the biofertilizers regulate nutrient uptake process and prolonged vase life phenomenon. Bekheta and Mahgoub (2005) concluded that the increase in nitrogen level lead to change in amino acids quantity and specific proteins in carnation plants. Plants treated with microbial inoculations showed more sugar contents. 


\section{Conclusion}

The study discusses that the poultry manure at the rate of $2 \%$ of soil weight improves vegetative growth of Gladiolus (Gladiolus hybrida) as well as flower characteristics. Moreover, inoculation by Azospirillum brasilense and Bacillus subtilis increases the plant height, chlorophyll intensity, N, P, K uptake and flower quality in autumn and spring seasons. Since the soils of Sulaimani farms are suffering from organic matter deficiency, application of animal residue as poultry manure is used as it improves organic matter content. Furthermore, using biofertilizer is safer than chemical fertilizer to decrease soil pollution, and it costs less. It is clear that the irrigation with magnetic water and using bacteria Azosperilum spp. can improve flower production and reduced salinity of the soil. It is recommended for future researches to study the different type of bacteria and mycorrhiza with organic matter.

\section{REFERENCES}

[1] Abdelaziz, E., Abdelrazig, A. (2014): Impact of magnetized water on elements contents in plants seeds. - International Journal of Scientific Research and Innovative Technology 1(4): 12-21.

[2] Al-Khazan, M., Abdullatif, B. M., Al-Assaf, N. (2011): Effects of magnetically treated water on water status, chlorophyll pigments and some elements content of Jojoba (Simmondsia chinensis L.) at different growth stages. - African Journal of Environmental Science and Technology 5(9): 722-731.

[3] Al-Maathidi, A. (2006): Effect of magnetic technology on some ornamental plants. $\mathrm{PhD}$. Thesis, College of Agriculture, University of Baghdad.

[4] Aladjadjiyan, A. (2002): Study of the influence of magnetic field on some biological characteristics of Zea mais. - Journal of Central European Agriculture 3(2): 89-94.

[5] Ali, A., Mehmood, T., Hussain, R., Bashir, A., Najam-Ud-Din, S., Ahmad, A. (2014): Investigation of biofertilizers influence on vegetative growth, flower quality, bulb yield and nutrient uptake in gladiolus (Gladiolus grandiflorus L.). - International Journal of Plant, Animal and Environmental Sciences 4(1): 94-99.

[6] Atak, Ç., Yurttaş, B., Yalçın, S., Mutlu, D., Rzakoulieva, A., Danilov, V. (1997): Effects of Magnetic Field on Soybean (Glycine Max. L. Merrill) Seeds. - Com JINR, Dubna.

[7] Bot, A., Benites, J. (2005): The Importance of Soil Organic Matter: Key to DroughtResistant Soil and Sustained Food Production. - Food \& Agriculture Org., Rome.

[8] Bekheta, M. A., Mahgoub, M. H. (2005): Application of kinetin and phenylalanine to improve flowering characters, vase life of cut flowers as well as vegetative growth and biochemical constituents of carnation plants. - Egypt Academic Journal Biological Science 20(6): 234-246.

[9] Bhalla, R., Kanwar, P., Dhiman, S. and Jain, R. (2006) 'Effect of biofertilizers and biostimulants on growth and flowering in gladiolus', Journal of Ornamental Horticulture, 9(4), pp. 248-252.

[10] Chaitra, R., Patil, V. (2007): Effect of integrated nutrient management on growth, yield and quality of China aster (Callistephus chinensis (L.) Nees). - Karnataka J. Agric. Sci. 20: 689-90.

[11] Dhawi, F., Al-Khayri, J. M. (2009): Magnetic fields induce changes in photosynthetic pigments content in date palm (Phoenix dactylifera L.) seedlings. - The Open Agriculture Journal 3(1). 
[12] Eşitken, A., Turan, M. (2004): Alternating magnetic field effects on yield and plant nutrient element composition of strawberry (Fragaria $\mathrm{x}$ ananassa cv. Camarosa). - Acta Agriculturae Scandinavica, Section B-Soil \& Plant Science 54(3): 135-139.

[13] Garg, S., Bahl, G. (2008): Phosphorus availability to maize as influenced by organic manures and fertilizer $\mathrm{P}$ associated phosphatase activity in soils. - Bioresource Technology 99(13): 5773-5777.

[14] Greving, A. J. (1987): G87-852 Growing Gladiolus. - Historical Materials from University of Nebraska-Lincoln Extension.

[15] Gutiérrez-Mañero, F. J., Ramos-Solano, B., Probanza, A., Mehouachi, J., R Tadeo, F., Talon, M. (2001): The plant-growth-promoting rhizobacteria Bacillus pumilus and Bacillus licheniformis produce high amounts of physiologically active gibberellins. Physiologia Plantarum 111(2): 206-211.

[16] Hashemabadi, D., Zaredost, F., Solimandarabi, M. J. (2015): The effect of magnetic water and irrigation intervals on the amount of the nutrient elements in soil and aerial parts of periwinkle (Catharanthus roseus L.). - Journal of Ornamental \& Horticultural Plants 5(3).

[17] Hozayn, M., Qados, A. A. (2010): Magnetic water application for improving wheat (Triticum aestivum L.) crop production. - Agriculture and Biology Journal of North America 1(4): 677-682.

[18] Jackson, M. L. (1958): Soil Chemical Analysis. - Prentice-Hall, Englewood Cliffs, NJ.

[19] Jha, S. (2011): Studies on Integrated Nutrient Management in Gladiolus with Special Reference to Growth, Yield and Flowering Quality. - Indira Gandhi Krishi Vishwavidyalaya, Raipur.

[20] Kumari, M. (2014): Postharvest Studies in Chrysanthemum (Dendranthema grandiflorum L.). - Division of Floriculture and Landscaping, New Delhi.

[21] Manning, J., Goldblatt, P. (2008): The Iris Family: Natural History and Classification. - Timber Press, Portland, OR, pp. 91-93.

[22] Mazhar, Azza, A. M., Nahed, G., Abd El Aziz, E. El Habba (2010): Impact of different soil media on growth and chemical constituents of Jatropha curca L. seedlings growth under water regime. - Journal of American Science 6(8): 549-556.

[23] Olsen, S. R., Sommers, L. E. (1982): Phosphorus. - In: Page, A. L. (ed.) Methods of Soil Analysis. Part 2. Chemical and Microbiological Properties. 2nd Ed. Amer. Soc. of Agron. Inc. Soil. SOCOM, Madision, WI.

[24] Orhan, E., Esitken, A., Ercisli, S., Turan, M., Sahin, F. (2006): Effects of plant growth promoting rhizobacteria (PGPR) on yield, growth and nutrient contents in organically growing raspberry. - Scientia Horticulturae 111(1): 38-43.

[25] Page, A. L., Miller, R. H. Keeug, D. R. (1982): Methods of Soil Analysis. Part 2: Chemical and Microbiological Properties. - Amer. Soc. Agron., Madison, WI.

[26] Pang, X., Deng, B. (2008): Investigation of changes in properties of water under the action of a magnetic field. - Science in China Series G: Physics, Mechanics and Astronomy 51(11): 1621-1632.

[27] Pietruszewski, S. (1999): Influence of pre-sowing magnetic biostimulation on germination and yield of wheat. - International Agrophysics 13: 241-244.

[28] Ranganna, S. (1977): Manual Analysis of Fruit and Vegetable Products. Method II. Tata McGraw-Hill Publishing Company Limited, New Delhi.

[29] Sajjad, Y., Jaskani, M. J., Ashraf, M. Y., Qasim, M., Ahmad, R. (2014): Response of morphological and physiological growth attributes to foliar application of plant growth regulators in gladiolus white prosperity. - Pak. J. Agri. Sci. 51(1): 123-129.

[30] Shah, S. T., Ghafoor, F., Khan, N., Sajid, M., ul Amin, N., Shah, Z., Bibi, S., Ahmad, T., ul Haq, F. (2016): Organic fertilizers affect the growth attributes of weeds and Swiss chard. - Pakistan Journal of Weed Science Research 22(3).

[31] Singh, Y. (2009): Studies on the use of biofertilizers in gladiolus. - PhD. Thesis, Agricultural University, Hisar. 


$$
\text { - } 2655 \text { - }
$$

[32] Srivastava, R., Govil, M. (2005): Influence of biofertilizers on growth and flowering in gladiolus cv. American Beauty. - International Conference and Exhibition on Soilless Culture: ICESC 742: 183-188.

[33] Tahir, N. A.-R., Karim, H. F. H. (2010): Impact of magnetic application on the parameters related to growth of chickpea (Cicer arietinum L.). - Jordan Journal of Biological Sciences 3(4): 175-184.

[34] Yazdani, M., Bahmanyar, M. A., Pirdashti, H., Esmaili, M. A. (2009): Effect of phosphate microorganisms (PSM) and plant growth solubilization promoting rhizobacteria (PGPR) on yield and yield components of corn (Zea mays L.). International Journal of Biological, Biomolecular, Agricultural, Food and Biotechnological Engineering 3(1). 